\title{
Seismotectonics of the 2018 northern Osaka M6.1 earthquake and its aftershocks: joint movements on strike-slip and reverse faults in inland Japan
}

\author{
Miroslav Hallo ${ }^{1^{*}} \mathbb{0}$, Ivo Opršal $^{2}$, Kimiyuki Asano ${ }^{3}$ and František Gallovič ${ }^{1}$
}

\begin{abstract}
On June 18, 2018, an $\mathrm{M}_{\mathrm{JMA}} 6.1$ inland crustal earthquake occurred on the northeast edge of the Osaka basin, Japan. This event impacted the region by the maximum PGA larger than $0.9 \mathrm{~g}$, and it was followed by a series of weaker aftershocks. The earthquakes were located near the Arima-Takatsuki Tectonic Line (ENE-WSW dextral strike-slip faults) and the Uemachi fault system ( $\mathrm{N}-\mathrm{S}$ reverse faults), hence the seismotectonic interpretations we assumed to be rather complex. Here we propose a seismotectonic model of this sequence based on seismological data and stress field considerations. In particular, we infer to a centroid moment tensor for the mainshock using Bayesian full-waveform inversion from strong motion records. The solution of $M_{w} 5.6$ involved a significant CLVD component, which we interpreted as being due to rupture process on a complex fault geometry. Decomposition of the non-DC moment tensor into major and minor pure-shear moment tensors suggests a combination of strike-slip and reverse faulting mechanisms. We also analyzed the 108 strongest aftershocks with $M_{\text {JMA }}$ between 2.0 and 4.1 using records from broadband and short-period stations. Aftershocks' moment tensors inverted from $P$-wave amplitudes exhibit mainly strike-slip and reverse faulting mechanisms, having significant spatial variations. The local stress field inverted from these mechanisms had a dominant maximum (compressional) principal stress $\sigma_{1}$ in ESE-WNW direction, while $\sigma_{2} \cong \sigma_{3}$. Both ENEWSW dextral strike-slip and N-S reverse faults can be active in such stress field as observed in the mainshock (without any need for stress spatial inhomogeneity). To conclude, the activated strike-slip fault is parallel to the Arima-Takatsuki Tectonic Line. The activated $\mathrm{N}-\mathrm{S}$ reverse fault is dipping to east by $50^{\circ}$ similarly as the Uemachi fault system. Joint shear movements on both of these faults contributed significantly to the total seismic moment of the mainshock.
\end{abstract}

Keywords: Seismotectonics, Osaka, Takatsuki, Earthquake source, Bayesian inversion, Moment tensor, Stress field, Complex faulting, Kinki triangle, 2018 Northern Osaka earthquake

\section{Introduction}

The 2018 northern Osaka earthquake mainshock-aftershocks sequence was started on June 18, 2018 (07:58 of Japan Standard Time), by an $\mathrm{M}_{\mathrm{JMA}} 6.1$ mainshock. The hypocenter was located by the Japan Meteorological Agency (JMA) at a depth of $13 \mathrm{~km}$ under Takatsuki city $\left(34.844^{\circ} \mathrm{N}, 135.622^{\circ} \mathrm{E}\right)$ in the Osaka metropolitan area,

\footnotetext{
*Correspondence: hallo@karel.troja.mff.cuni.cz

${ }^{1}$ Faculty of Mathematics and Physics, Charles University, Prague, Czech Republic

Full list of author information is available at the end of the article
}

Kansai, Japan (see Fig. 1). This event generated strong ground motions in the near-source region, causing damage on a local scale and four casualties. The earthquake damage and response are briefly summarized in Hirata and Kimura (2018). The maximum measured peak ground acceleration (PGA) exceeded $0.9 \mathrm{~g}$, and the instrumental intensity in the epicentral area reached a degree 6-lower of the 7-degree JMA scale. There is no observed surface rupture, and no significant surface deformation was reported by InSAR analysis. The source mechanism of this earthquake has been routinely investigated by JMA, National Research Institute for Earth 


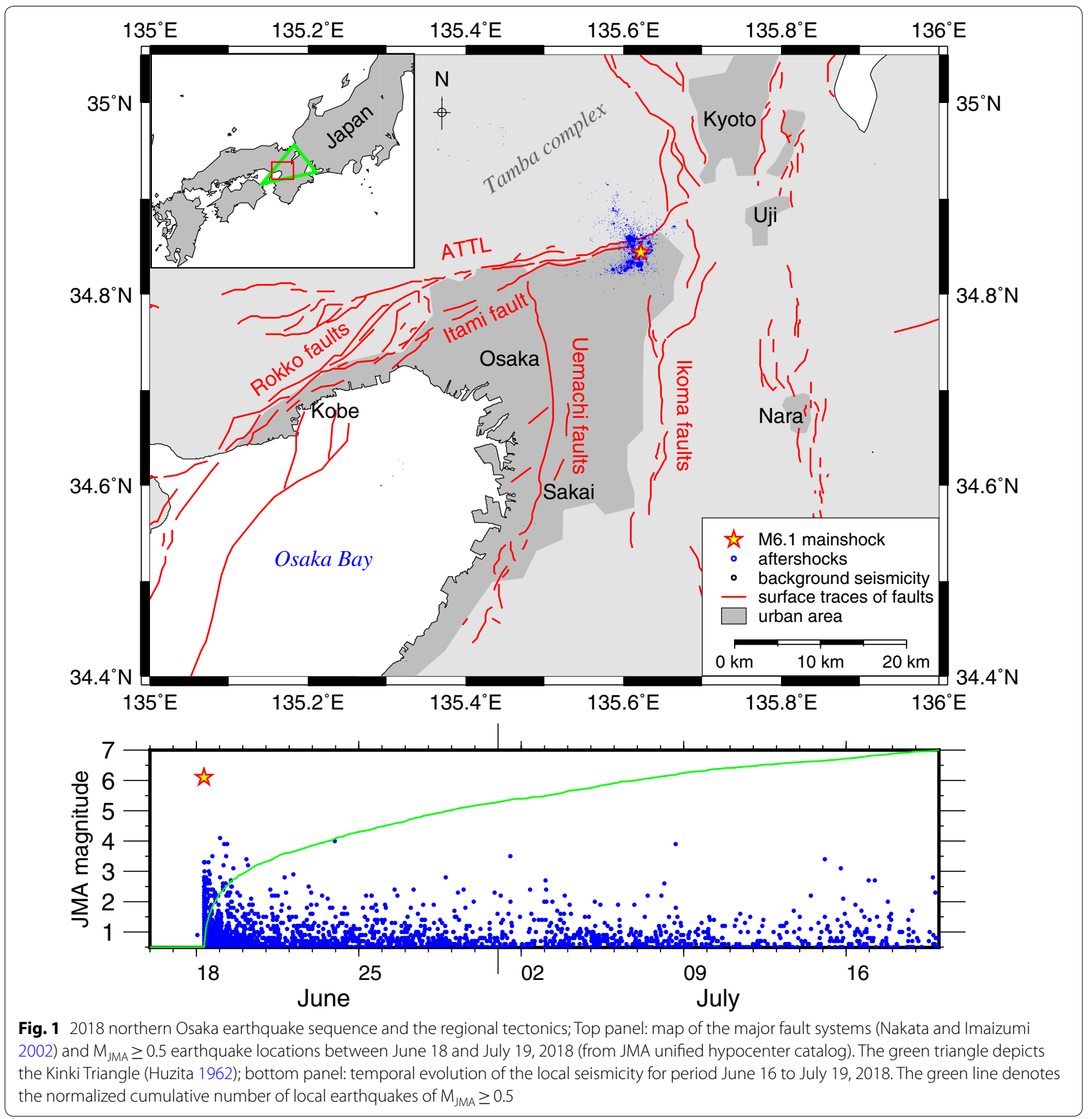

Science and Disaster Resilience (NIED) and other agencies (see Table 1). The centroid moment tensor (CMT) has compressional $P$-axis along the ESE-WNW direction, and it contains large non-shear components. The mainshock was followed by a sequence of weaker aftershocks not exceeding $\mathrm{M}_{\mathrm{JMA}}$ 4.1. In total, JMA unified hypocenter catalog for Japan comprises 2140 local events of $\mathrm{M}_{\mathrm{JMA}} \geq 0.5$ in the period June 18-July 19, 2018 (see bottom panel in Fig. 1).
The Osaka metropolitan area consists of a population exceeding eight million and is the economical center of western Japan. It is the heart of the Osaka-Kobe-Kyoto urban area (i.e., the second-most populated region in Japan), and it has a remarkable role in the global economy. There are several active faults within the region (Fig. 1, Nakata and Imaizumi 2002; Research Group for Active Faults of Japan 1991), including E-W to NESW trending dextral strike-slip faults and $\mathrm{N}-\mathrm{S}$ trending 
Table 1 Source mechanism for the $M_{J M A} 6.1$ northern Osaka mainshock by other agencies

\begin{tabular}{|c|c|c|c|c|c|c|}
\hline Agency & Technique & Mechanism & Depth (km) & Strike/dip/rake & DC & $M_{\mathrm{w}}$ \\
\hline JMA & 1st motion polarity & Reverse & 13 & $356^{\circ} / 38^{\circ} / 60^{\circ}$ & - & - \\
\hline NIED & MT & Strike-slip & 11 & $49^{\circ} / 73^{\circ} / 153^{\circ}$ & $26 \%$ & 5.5 \\
\hline USGS & CMT & Strike-slip & 11 & $54^{\circ} / 61^{\circ} / 164^{\circ}$ & $26 \%$ & 5.55 \\
\hline Global CMT & СMT & Strike-slip & 17 & $50^{\circ} / 54^{\circ} / 157^{\circ}$ & $21 \%$ & 5.6 \\
\hline
\end{tabular}

reverse faults. The importance of these faults was highlighted by the disastrous $1995 \mathrm{M}_{\mathrm{w}} 6.9\left(\mathrm{M}_{\mathrm{IMA}} 7.2\right)$ Hyogoken-Nanbu (Kobe) earthquake resulting from dextral strike-slip movements on NE-SW trending Rokko-Awaji Shima Fault Zone (e.g., Kanamori 1995; Katao et al. 1997). The Osaka metropolitan area is bounded on the north by the Arima-Takatsuki Tectonic Line (ATTL), which is the ENE-WSW dextral strike-slip fault system. $\mathrm{N}-\mathrm{S}$ trending Uemachi fault zone is an east-dipping reverse active fault system with surface traces across the center of Osaka (see Fig. 1). According to the Headquarters for Earthquake Research Promotion (HERP) (2004), the Uemachi fault has an average vertical slip rate of $0.4 \mathrm{~mm} /$ year, having potential to generate an earthquake of magnitude 7.5 with the recurrence interval of 8000 years. HERP (2004) estimated this recurrence interval, based on the average vertical slip rate and an empirically estimated vertical displacement per one event. Because it is difficult to conduct paleoseismological surveys in urbanized area, the latest event and actual recurrence interval are still unresolved. Sugiyama et al. (2003) reported that the most recent event occurred between about $9.5 \mathrm{ka}$ and $25 \mathrm{ka}$ based on a joint survey by highresolution $\mathrm{S}$-wave reflection profiling and continuous coring across the fault in Central Osaka. Recently, Sugito and Kondo (2015) reported that the latest event occurred roughly 2400 years BP based on newly conducted paleoseismological surveys and geomorphic changes around the fault system. There are no known events for the Uemachi fault system in historical period, and it might cause a large-scale disaster in the worst-case scenarios. The 2018 northern Osaka earthquake sequence occurred near the junction of eastern part of the ATTL and the deeper part of the Uemachi east-dipping fault (see Fig. 1); hence, the relationship between the activated structure and nearby faults should be investigated in detail.

In this study, we infer and analyze source mechanism of the $\mathrm{M}_{\mathrm{JMA}} 6.1$ mainshock. The CMT solution is inferred to using recently developed Bayesian approach considering uncertainties of Greens' functions (GFs) originating from the imperfect knowledge of the Earth's crust (Hallo and Gallovič 2016; Hallo et al. 2017). The solution is complemented by reliable estimates of its uncertainty, which permits the subsequent interpretation of its inferred relatively large non-shear component. In order to support and complete the interpretation, we analyzed the 108 strongest aftershocks with $\mathrm{M}_{\mathrm{IMA}}$ between 2.0 and 4.1. The hypocenters of these events were located using manually picked arrival times of direct $P$ - and $S$-waves and supplemented by location uncertainties. Then, we inferred to aftershocks' deviatoric moment tensors (MTs) from $P$-wave amplitudes considering also their uncertainties. The pure-shear components of the inferred MTs are used for inversion of the local stress field. Finally, our results were used to propose a seismotectonic model.

\section{Tectonic setting}

The 2018 northern Osaka earthquakes occurred in the upper crust near the northeast edge of the Osaka basin in the southwestern corner of the Kinki Triangle (see Fig. 1). The Kinki Triangle is a triangular-shaped area in central Kansai (Kinki), surrounded by the Bays of Osaka (southwest), Wakasa (north) and Ise (southeast). It is characterized by several ellipsoidal basins bounded by narrow mountain ranges accompanied by many faults (Huzita 1962).

The geotectonic development of the Kinki Triangle is well documented by sedimentation of the Setouti Series in depression zones since the opening of the Japan Sea in Miocene (Huzita 1962, 1969). The depressions zones (i.e., synclines) filled with mid-Miocene sediments were formed in the stress field with $\mathrm{N}-\mathrm{S}$ trending maximum (compressional) principal stress. The latter structures filled by Pleistocene sediments are almost perpendicular to them; thus, the principal stress directions were rotated horizontally by almost 90 degrees. It indicates that E-W trending reverse faults occurred in the Kinki Triangle earlier than the reverse faults of the N-S trend. Some of the older E-W reverse faults have then switched to strike-slip regime, by later recently still active movements (Huzita 1969). Indeed, the recent crustal regional maximum principal stress trends in $\mathrm{E}-\mathrm{W}$ direction as indicated by CMTs (Terakawa and Matsuura 2010) and in situ stress measurements (Tanaka 1985). Matsushita and Imanishi (2015) show that the stress field in the Osaka area has significant spatial variations with maximum principal stress $\sigma_{1}$ trending sub-horizontally from ESE-WNW to ENE-WSW. The $\sigma_{1}$ is there clearly 
differentiated from intermediate and minimum principal stresses $\left(\sigma_{1} \gg \sigma_{2}>\sigma_{3}\right)$. The $\sigma_{2}$ and $\sigma_{3}$ principal stresses rotate in the region around the $\sigma_{1}$ direction, which results in the spatial variations in stress field. Such spatially dependent stress regime allows for occurrence of active strike-slip faults close to reverse faults. Nevertheless, the stress field for this particular area of the 2018 northern Osaka earthquakes has not been described in detail yet.

Borders of the southwest Kinki Triangle are formed by major active strike-slip fault zones. The southern border (beyond the border of the detailed map in Fig. 1) is formed by the Median Tectonic Line, the largest tectonic line in southwestern Japan (e.g., Okada 1980). Next, the Rokko-Awaji Shima Fault Zone (Rokko faults on Honshu Island) and the ATTL separate the basin regions (within the Kinki Triangle) from the mountain ranges on northwest (see Fig. 1). The Rokko fault system consists of several parallel active strike-slip faults trending in NE-SW. According to Maruyama and Lin (2000), these faults have dextral slip rates of $1.0-1.3 \mathrm{~mm} /$ year with a minor vertical component of $0.3-0.4 \mathrm{~mm} /$ year. The ATTL is an ENE-WSW trending dextral strike-slip fault system situated between the Rokko faults and southwest Kyoto (Fig. 1). Maruyama and Lin (2002) deduce that the ATTL has been active since mid-Miocene to recent, and the pre-Neogene basement rocks have been displaced along it dextrally by $16-18 \mathrm{~km}$. The recent predominant strikeslip movements with horizontal slip rates of $1-3 \mathrm{~mm} /$ year are accompanied by minor vertical component ( $0.3 \mathrm{~mm} /$ year).

The tectonics inside the Kinki Triangle is characterized by the N-S trending active reverse faults (Research Group for Active Faults of Japan 1991). These faults are mostly east-dipping in the Osaka basin and west-dipping in the Ise basin. The predominant E-W contraction in the upper crust forms the uplifted mountains between Osaka and Ise basins as a pop-up structure (e.g., Sato et al. 2009). There are two major east-dipping reverse active fault systems in the Osaka basin (e.g., Nakata and Imaizumi 2002; Sato et al. 2009): (1) The N-S trending Uemachi fault zone crosses the center of Osaka city (see Fig. 1). It is a $42-\mathrm{km}$-long zone of reverse faults dipping $40^{\circ}-60^{\circ}$ to the east, though the deeper segments have smaller (thrust-like) dip angle. (2) The Ikoma fault zone runs approximately $12 \mathrm{~km}$ eastwards to the Uemachi fault zone, forming the eastern boundary of the Osaka basin (see Figs. 1, 2). The recent vertical slip rates of both of these fault zones are estimated as $>0.4 \mathrm{~mm} /$ year (Nakata and Imaizumi 2002).

The 2018 northern Osaka $\mathrm{M}_{\mathrm{JMA}} 6.1$ mainshock does not overlap spatially with any particular significant earthquake since the beginning of instrumental earthquake monitoring in Japan, which started 1873. Nevertheless, the Kinki region has been affected by two disastrous crustal inland earthquakes in the historical age. The earlier 1596 Keichou-Fushimi earthquake $(M>7.5)$ was probably caused by linked movements on both ATTL and Rokko-Awaji Shima fault zone (e.g., Ishibashi 2004, Kamai and Sangawa 2011). The later disastrous $M_{w} 6.9$ $\left(\mathrm{M}_{\mathrm{IMA}} 7.2\right)$ Hyogoken-Nanbu, Kobe, earthquake (January $17,1995)$ resulted from dextral strike-slip movements on several parallel faults of the Rokko-Awaji Shima fault zone (e.g., Kanamori 1995). This event was followed by an aftershock sequence distributed predominantly along the mainshock rupture zone. According to Katao et al. (1997), the aftershocks had mainly strike-slip or reverse mechanisms with a nodal plane parallel to a known active fault. The azimuths of $P$-axes trended sub-horizontally from E-W to ESE-WNW. The exception was the largest $\mathrm{M}_{\mathrm{JMA}} 5.4$ aftershock (07:38 of Japan Standard Time, January 17,1995$)$ located near Itami city, east from the mainshock rupture zone. This event had a strike-slip mechanism with $P$-axis in NW-SE direction and one nodal plane being in agreement with the Itami fault strike (see Fig. 1).

To complete, the regional background (micro-)seismicity within the Osaka basin is quite low. It is distributed mainly in the Jurassic Tamba accretionary complex (e.g., Wakita 2013), and it is sharply bounded by the ATTL to the south (e.g., Katao et al. 1997; Matsushita and Imanishi 2015), see Fig. 1 . The hypocenters are located in the seismogenic upper crust at depths shallower than $16 \mathrm{~km}$. Sato et al. (2009) assign the cutoff depth of crustal seismicity to mid-crustal detachment connected to the local thermal regime.

\section{Methods}

Here we describe main methods used to analyze the mainshock and aftershock seismological data.

\section{Bayesian inference of CMT}

In the low frequency point source approximation, the earthquake source model can be described by the centroid moment tensor (CMT, e.g., Aki and Richards 2002, pp. 49-52). The CMT is inferred from observed waveforms by inverse modeling, which is subject to uncertainty (e.g., Zahradník and Custódio 2012). In the case of large earthquakes, the major source of uncertainty is related to the modeling uncertainty due to the imprecise knowledge of the velocity model considered (e.g., Duputel et al. 2012). The uncertainty of an inferred CMT solution is thus governed by imprecise modeling of the GFs representing response of Earth's crust to an impulse stimulus (e.g., Yagi and Fukahata 2011). The imprecise GFs is the major source of uncertainties, but seismic noise can also play an important role. However, this is mostly the 


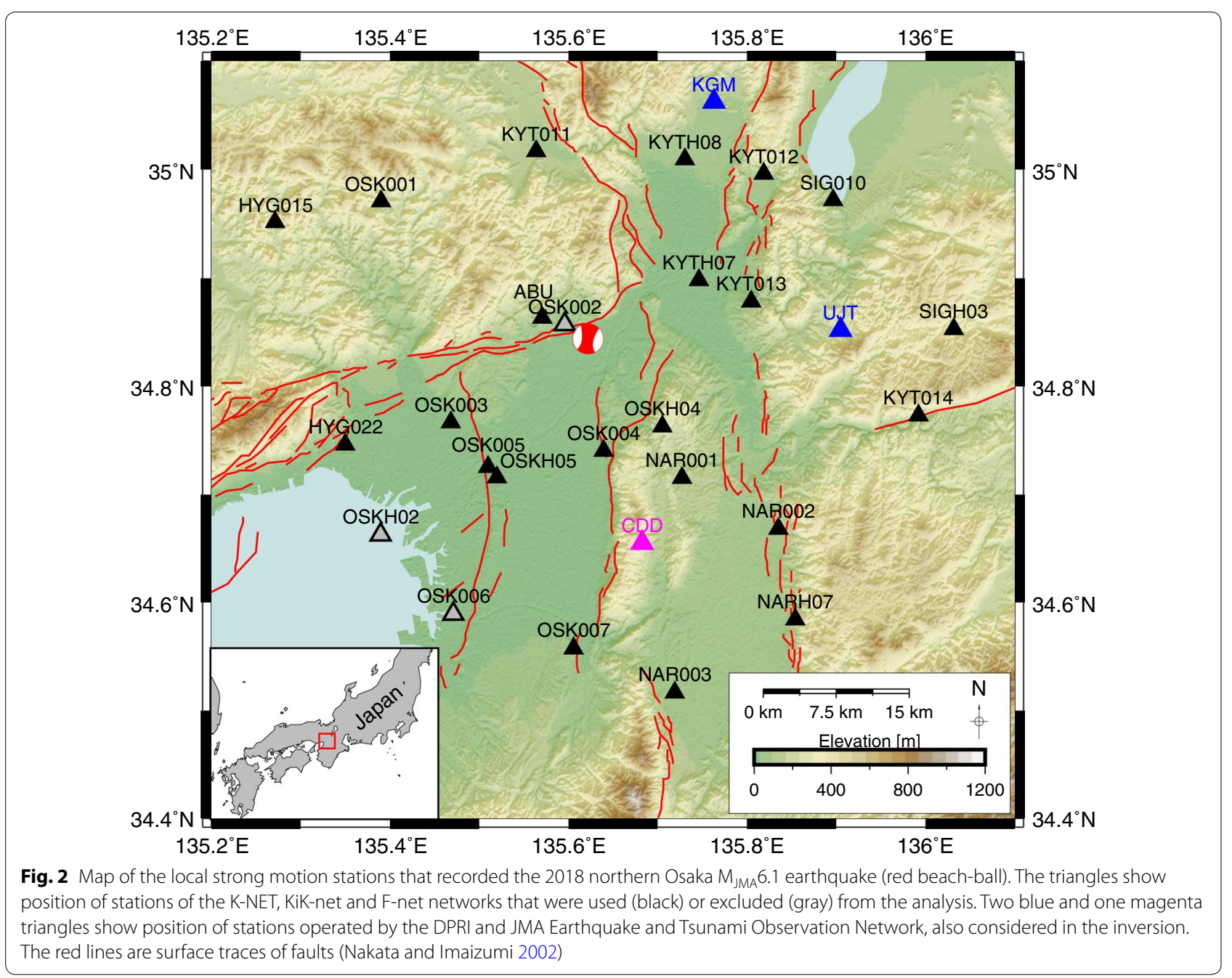

case of weaker events with lower signal-to-noise ratio (e.g., Vackář et al. 2017).

For the CMT inversion, we fit displacement waveforms using a modified version of the Bayesian full-waveform CMT inversion code ISOLA-ObsPy (Vackár et al. 2017). The code uses a hybrid combination of determining the full moment tensor by linear least-squares approach and centroid location and time by grid search (e.g., Zahradník and Sokos 2018). The full-wavefield GFs are computed by the discrete wavenumber method (Bouchon 1981) in $1 \mathrm{D}$ velocity model consisting of homogenous layers. The modeled wavefield includes body waves, surface waves as well as the near-field terms. The modeling uncertainty (i.e., inaccuracy of GFs) is included following the approach by Hallo and Gallovič (2016).

The inverse problem is solved in the Bayesian framework (Tarantola 2005), which leads to the maximum likelihood solution estimate supplemented by the posterior probability density (PDF) on model parameters.
This posterior PDF can be used to generate ensemble of random possible solutions drawn from the multivariate normal distribution. Such ensemble allows us to inspect marginal PDFs (marginal histograms) of any parameter of the CMT solution, including non-linearly related parameters. These marginal PDFs are fitted with Gaussian functions defined by means and standard deviations $\sigma$. The reliable estimate of the uncertainty of CMT parameters proved to be beneficial in terms of interpretation of the results (e.g., Hallo et al. 2017; Liu et al. 2018; Ma et al. 2018; Mustać et al. 2018).

\section{Major and minor moment tensor decomposition}

The seismic moment tensor (MT) may contain non-shear force equivalents (e.g., Frohlich 1994). The most widely used decomposition of non-shear MTs into ISO, DC and CLVD components proved to be useful for physical interpretation of earthquake sources in general. Nevertheless, Jost and Herrmann (1989) pointed out that other 
decompositions are mathematically possible and may be suitable in some specific cases. Following Kanamori and Given (1981), a deviatoric MT (i.e., MT with subtracted ISO component) can be decomposed into major and minor DC MTs. The major DC MT is the best approximation of a non-shear (non-DC) MT by a shear (DC) source. By analogy to Wallace (1985), assuming absolute values of deviatoric MT eigenvalues $\left|\lambda_{1}\right| \geq\left|\lambda_{2}\right| \geq\left|\lambda_{3}\right|$ with respective eigenvectors $\boldsymbol{v}_{1}, \boldsymbol{v}_{2}$, and $\boldsymbol{v}_{3}$, the major and minor DC MTs with preserved dominant axis can be expressed as follows:

$$
\begin{aligned}
& \mathbf{M}_{\text {major }}=\lambda_{2}\left(-\boldsymbol{v}_{1}^{T} \boldsymbol{v}_{1}+\boldsymbol{v}_{2}^{T} \boldsymbol{v}_{2}\right) \\
& \mathbf{M}_{\text {minor }}=\lambda_{3}\left(-\boldsymbol{v}_{1}^{T} \boldsymbol{v}_{1}+\boldsymbol{v}_{3}^{T} \boldsymbol{v}_{3}\right) .
\end{aligned}
$$

The deviatoric condition $\lambda_{1}+\lambda_{2}+\lambda_{3}=0$ applies. The dominant eigenvector $\boldsymbol{v}_{1}$ refers to direction of either $P$ or $T$-axis, based on the sign of dominant eigenvalue $\lambda_{1}$ (Hallo et al. 2017). The dominant axis direction is then preserved for both the major and minor DC MTs. Hallo et al. (2017) utilized the mathematical formulation of the major and minor DC MT decomposition with preserved $T$-axis for the case of complex earthquakes (2016 Kumamoto sequence, Japan) in the tectonic stress field with dominant minimal principal stress $\sigma_{3}\left(\sigma_{1} \cong \sigma_{2}>\sigma_{3}\right)$. Then, both of the decomposed MTs may be physically interpreted by the complex geometry of the rupture. Nevertheless, it is necessary to emphasize that the physical interpretation of the major and minor DC MTs has to be supported by other evidences stemming from, e.g., local tectonic settings, source mechanisms of other events, or slip inversion on a segmented fault, such as done in the present study.

\section{MT inversion from $P$-wave amplitudes}

MT for weaker events (e.g., aftershocks) can be inverted from amplitudes of direct $P$-waves. Let us assume a direct body wave spreading from a point source (MT at source position $\xi$ ) in a layered medium. The observed $P$-wave far-field displacement at receiver position $\boldsymbol{x}$ has pulse-like shape with a dominant frequency $f_{0}$. The displacement amplitude depends on the $P$-wave radiation pattern, geometrical spreading and intrinsic attenuation. The amplitude of $n$th component of the $P$-wave displacement $u_{n}^{P}$ can be expressed, in the ray approximation, as (utilizing Aki and Richards 2002, Eq. 4.29)

$$
u_{n}^{P}(\boldsymbol{x})=\frac{1}{2 \pi f_{0}} \frac{\gamma_{n} \gamma_{i} \gamma_{j} M_{i j}}{4 \pi \rho v_{P}^{3}} \frac{1}{r} \exp \left(-\pi t^{*} f_{0}\right),
$$

where $r$ is the ray path length, vector $\gamma$ consists of directional cosines of outgoing rays and Einstein summation convention (indexes $i$ and $j$ ) applies. $M_{i j}$ is a component of the moment tensor, and $\nu_{P}$ and $\rho$ are $P$-wave velocity and density at the source zone, respectively. The intrinsic attenuation is managed by $t^{*}$ factor, which is inverse of quality factor multiplied by $P$-wave slowness integrated along the ray path, i.e., $t^{*}=\int \frac{1}{Q p v_{P}} \mathrm{~d}$. The frequency of the $P$-wave $f_{0}$ plays a role in the attenuation part of the equation, and hence, it influences the scalar seismic moment $M_{0}$ estimation. However, the aim is to interpret mainly DC mechanisms. In our particular application, the directional cosines of outgoing rays are determined by ray tracing method in 1D velocity model from Table 2 .

For the purpose of inversion, Kikuchi and Kanamori (1991) proposed to represent the deviatoric moment tensor $M_{i j}$ by a linear combination of five elementary MTs defined therein. The $P$-wave amplitudes on all stations are pre-computed for these elementary MTs, and then, the five respective linear coefficients (model parameters) can be determined by least-squares approach (in analogy to Zahradník and Sokos 2018). The linear inverse problem for deviatoric MT is solved in the Bayesian probabilistic framework (Tarantola 2005, Eq. 1.100). The assumed diagonal data covariance matrix has station-constant variance of $25 \%$ of maximum $P$-wave amplitude squared over the all 3 components, i.e., $\sigma_{\text {station }}^{2}=0.25 \cdot \max \left(u_{E}^{2}, u_{N}^{2}, u_{Z}^{2}\right)$. Such estimates of amplitude uncertainty are rather conservative, leading thus to conservative estimates of the MT solution uncertainty.

\section{Analysis of the M6.1 mainshock}

Here we analyze the source mechanism of the $M_{I M A} 6.1$ mainshock as the most significant earthquake in the sequence.

\section{Data}

We use strong motion recordings from epicentral distances of 5 to $40 \mathrm{~km}$ for the source analysis. Specifically,

Table 2 1D crustal velocity model determined from the 3D Japan Integrated Velocity Structure Model (Koketsu et al. 2012) considered for calculation of Green's functions

\begin{tabular}{llllll}
\hline $\begin{array}{l}\text { Top depth } \\
\text { of layers } \\
(\mathbf{k m})\end{array}$ & $\boldsymbol{v}_{\mathbf{p}}(\mathbf{k m} / \mathbf{s})$ & $\boldsymbol{v}_{\mathbf{s}}(\mathbf{k m} / \mathbf{s})$ & Density $\left(\mathbf{g} / \mathbf{c m}^{\mathbf{3}}\right)$ & $\boldsymbol{Q}_{\mathbf{p}}$ & $\boldsymbol{Q}_{\mathbf{s}}$ \\
\hline 0.00 & & & & & \\
1.75 & 5.833 & 2.697 & 2.562 & 632 & 372 \\
3.50 & 6.358 & 3.438 & 2.710 & 680 & 400 \\
5.50 & 6.400 & 3.733 & 2.784 & 680 & 400 \\
10.85 & 6.759 & 4.028 & 2.935 & 680 & 400 \\
15.90 & 7.492 & 4.495 & 3.197 & 737 & 434 \\
\hline
\end{tabular}


we use three-component waveforms recorded at 22 stations of the K-NET, KiK-net and F-net strong motion networks (see Fig. 2, Okada et al. 2004), operated by National Research Institute for Earth Science and Disaster Resilience (NIED). A few regional stations were excluded from the selection, as their waveforms exhibit a complex wavefield due to unaccounted crustal model complexity. Nevertheless, these stations are located on the edge of the area of interest (see gray triangles in Fig. 2). We also use strong motion velocity data (sensor type VSE-355G3) from two stations UJT and KGM operated by the Disaster Prevention Research Institute of Kyoto University (DPRI), and CDD station of the JMA Earthquake and Tsunami Observation Network at NaraHeguri (see Fig. 2).

Original accelerometric data (K-NET, KiK-net, and JMA) and strong motion velocity data corrected for the instrument response (F-net, and DPRI) are filtered by a bandpass filter and integrated into displacements. The used bandpass filter $0.08-0.15 \mathrm{~Hz}$ is determined empirically by manual inspection and processing of the waveforms. The high-pass filter corner frequency is as low as possible in terms of signal-to-noise ratio. The low-pass filter corner frequency is limited by corner frequency of the earthquake, i.e., the validity condition of the point source approximation in time. The waveform data from all 25 stations are downsampled after the filtration and integration to the sampling frequency of $1.25 \mathrm{~Hz}$.

\section{Velocity model}

For the wavefield modeling purpose, we use a 1D crustal velocity model consisting of homogenous layers that is suitable for the discrete wavenumber modeling method. The velocity model is prepared from the 3D Japan Integrated Velocity Structure Model (Koketsu et al. 2012) as a horizontal average over area of $40 \times 40 \mathrm{~km}$ around the mainshock epicenter (Table 2). The horizontal average is firstly calculated for a densely sampled set of depths. Densities and quality factors $\left(\mathrm{Q}_{\mathrm{P}}\right.$ and $\left.\mathrm{Q}_{\mathrm{S}}\right)$ of homogeneous layers of our final sparser velocity model are then determined as average values; the wave velocity averages are computed to preserve vertical travel times from the dense 1D model. The maximal velocity deviation of the 1D model from the original 3D model is less than $10 \%$ for depths larger than $1 \mathrm{~km}$ (see Additional file 1: Appendix I). The shallow layers show higher lateral heterogeneities, but they do not significantly affect the inversion using much longer wavelengths for earthquake source at the depth of the 2018 northern Osaka mainshock.

\section{CMT solution}

We perform Bayesian inference of full CMT (including ISO component) for the $\mathrm{M}_{\mathrm{JMA}} 6.1$ northern Osaka mainshock, taking into account crustal velocity model uncertainty of $10 \%$. The nonlinear centroid parameters are sought in a regular space-time grid of points with regular grid steps of $1.4 \mathrm{~km}$ in $3 \mathrm{D}$ within $12 \mathrm{~km}$ around the hypocenter reported by the JMA. As an ensemble of acceptable solutions, we generate 10,000 random possible solutions drawn from the posterior PDF (including both uncertainty of the centroid position, time and MT components).

The CMT solution with the best variance reduction in standardized waveforms of 63\% (see waveforms fit in Additional file 1: Appendix II) is located at latitude $34.844^{\circ} \mathrm{N}$, longitude $135.622^{\circ} \mathrm{E}$ and at depth of $10 \mathrm{~km}$ (red beach-ball in Fig. 2). The centroid location overlaps horizontally with the hypocenter location by JMA, yet it is located $3 \mathrm{~km}$ shallower (it may be influenced by the used velocity model). The centroid time is 07:58:36 of Japan Standard Time, and the solution has a scalar seismic moment of $2.78 \times 10^{17} \mathrm{Nm}\left(\mathrm{M}_{\mathrm{w}} 5.6\right)$. The CMT solution has the $P$-axis trending horizontally with azimuth in ESE-WNW direction. All CMT parameters are detailed in Table 3. The MT solution involves significant (negative) CLVD component of $-73 \%$ and $0 \%$ of ISO component (Fig. 3). The assessment of solution uncertainty supports the presence of significant CLVD component in the source model for the mainshock. The inferred solution with its uncertainty is very stable and well resolved due to the high-quality waveform records on many local stations. Hence, these described features of the mainshock source model can be assumed as reliable.

\section{Major and minor DC sources}

While the DC component of the MT has direct physical interpretation in terms of shear faulting, the significant CLVD component supplemented with negligible ISO points rather to the complexity of the faulting (e.g., Frohlich 1994). The complex faulting may be obvious for

Table 3 Parameters of the inferred CMT solution for the $M_{w} 5.6\left(M_{J M A} 6.1\right)$ northern Osaka mainshock

\begin{tabular}{|c|c|}
\hline Centroid lat/lon/depth & $34.844^{\circ} \mathrm{N} / 135.622^{\circ} \mathrm{E} / 10 \mathrm{~km}$ \\
\hline$M_{0}$ & $2.78 \times 10^{17} \mathrm{Nm}$ \\
\hline 1st Strike/dip/rake & $52^{\circ} / 77^{\circ} / 164^{\circ}$ \\
\hline 2nd Strike/dip/rake & $146^{\circ} / 74^{\circ} / 14^{\circ}$ \\
\hline DC/CLVD/ISO & 26\%/-73\%/0\% \\
\hline$M\left[M_{\mathrm{rr},} M_{\mathrm{tt},} M_{\mathrm{pp},} M_{\mathrm{rt},} M_{\mathrm{rp},} M_{\mathrm{tp}}\right]$ & $\begin{array}{l}{[1.101 .53-2.650 .260 .08} \\
\quad-0.72] \times 1 \mathrm{e} 17\end{array}$ \\
\hline Uncertainty (2ఠ): Horiz./vert. location & $<1.4 \mathrm{~km} /<1.4 \mathrm{~km}$ \\
\hline Uncertainty (2б): $\mathrm{M}_{0}$ & $0.7 \times 10^{1 /} \mathrm{Nm}$ \\
\hline Uncertainty (2б): Strike/Dip/Rake & $2.0^{\circ} / 5.0^{\circ} / 5.6^{\circ}$ \\
\hline Uncertainty (20): DC/CLVD/ISO & $6 \% / 6 \% / 8 \%$ \\
\hline
\end{tabular}



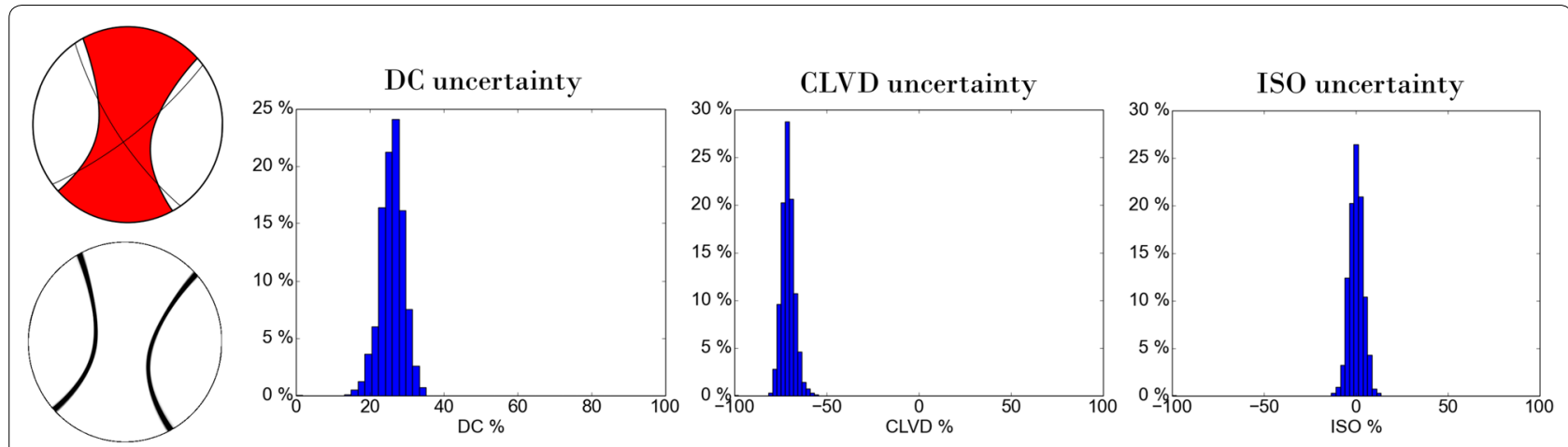

Fig. 3 Inferred CMT solution for the $M_{w} 5.6\left(M_{J M A} 6.1\right)$ northern Osaka mainshock. The beach-ball plot (top-left panel) corresponding to the best-fitting (maximum likelihood) solution estimate is supplemented by uncertainty estimate as captured by the whole posterior ensemble displayed in terms of nodal planes of all the solutions (the spherical plot in bottom-left panel) and marginal PDFs for DC, CLVD and ISO components (histograms in mid-right)

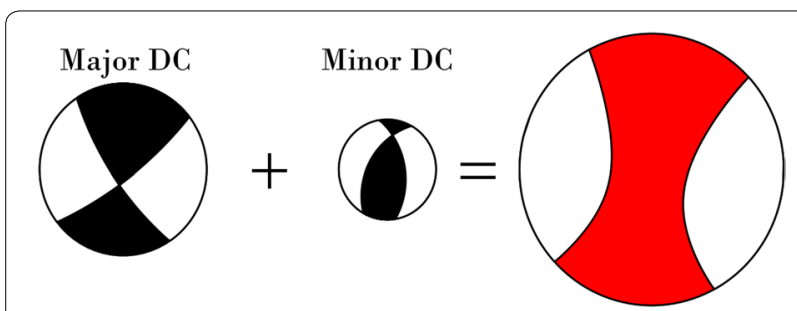

Fig. 4 Major and minor DC MT (black) decomposition of the best non-DC MT solution (red) for the $M_{w} 5.6\left(M_{J M A} 6.1\right)$ northern Osaka mainshock shown by trinity of beach-balls. The size of the beach-balls is proportional to their respective scalar seismic moment

large-size earthquakes like the $\mathrm{M}_{\mathrm{w}} 7.8$ Kaikoura earthquake (e.g., Ulrich et al. 2019) as it is supported by field observations (e.g., co-seismic surface ruptures). Nevertheless, it is much harder to reveal for midsize sources on buried faults like in our case. Hence, we take advantage of the knowledge of the full MT and decompose it into major and minor DC MTs assuming preserved $P$-axis (analogy to Wallace 1985; Hallo et al. 2017). Such decomposition is suitable for the northern Osaka area as there is dominant maximal principal tectonic stress $\sigma_{1}$ (Matsushita and Imanishi 2015) with its direction tilted from the $P$-axis only by roughly $15^{\circ}$.

Result of the major and minor DC MT decomposition of the best CMT solution for the northern Osaka mainshock is shown in Fig. 4 and Table 4. The non-DC MT is decomposed into a combination of strike-slip and reverse pure-shear faulting sources with scalar seismic moment ratios $63 \%$ and $37 \%$, respectively. Both of these DC mechanisms have horizontally trending $P$-axis with ESE-WNW azimuth, which is in accordance with regional stress field (e.g., Matsushita and Imanishi 2015). We would like to point out that the minor DC MT is engaged in a relatively large portion of the scalar seismic
Table 4 Decomposed major and minor DC MTs of the CMT solution for the $M_{w} 5.6\left(M_{J M A} 6.1\right)$ northern Osaka mainshock (preserving $\boldsymbol{P}$-axis)

\begin{tabular}{llrrr}
\hline & Mechanism & \multicolumn{1}{l}{$\begin{array}{l}\text { 1st Strike/dip/ } \\
\text { rake }\end{array}$} & $\begin{array}{l}\text { 2nd Strike/dip/ } \\
\text { rake }\end{array}$ & $\boldsymbol{M}_{\mathbf{0}}(\%)$ \\
\hline $\mathbf{M}_{\text {major }}$ & Strike-slip & $52^{\circ} / 77^{\circ} / 164^{\circ}$ & $146^{\circ} / 74^{\circ} / 14^{\circ}$ & 63 \\
$\mathbf{M}_{\text {minor }}$ & Reverse & $351^{\circ} / 50^{\circ} / 63^{\circ}$ & $210^{\circ} / 47^{\circ} / 119^{\circ}$ & 37 \\
\hline
\end{tabular}

moment of the whole non-DC MT. Hence, both of these two decomposed DC MTs contributed significantly to the non-DC source model of the $\mathrm{M}_{\mathrm{w}} 5.6\left(\mathrm{M}_{\mathrm{JMA}} 6.1\right)$ mainshock.

To assess uncertainties of mechanisms and moment ratios of the major and minor DC MTs, we perform repetitive decomposition with preserved $P$-axis of all non-DC MTs from the ensemble of solutions. The results shown in Fig. 5 then represent statistics from the 10,000 decomposed major and minor DC MTs. The orientation uncertainties $(2 \sigma)$ of strike/dip/rake angles are $2^{\circ} / 5^{\circ} / 5^{\circ}$ and $6^{\circ} / 3^{\circ} / 9^{\circ}$ for the major and minor DC fault planes, respectively. Note that these uncertainties result exclusively from the assumed inaccuracy of the velocity model.

\section{Analysis of the $\mathbf{M} \geq \mathbf{2 . 0}$ aftershocks}

Here we analyzed the 108 strongest northern Osaka sequence aftershocks with $\mathrm{M}_{\mathrm{JMA}} \geq 2.0$ between June 18 and July 19,2018 , when more than $75 \%$ occurred within 14 days after the $\mathrm{M}_{\mathrm{w}} 5.6\left(\mathrm{M}_{\mathrm{JMA}} 6.1\right)$ mainshock (see bottom panel in Fig. 1). The timing and magnitudes of these events were taken from the JMA unified hypocenter catalog. As these aftershocks are distinctly weaker than the mainshock $\left(\mathrm{M}_{\mathrm{JMA}} \leq 4.1\right)$, we used broadband and short-period stations and deployed different processing techniques. To improve the mainshock-aftershock consistency, we relocated the hypocenters of these events 
a

\section{Major DC uncert.}

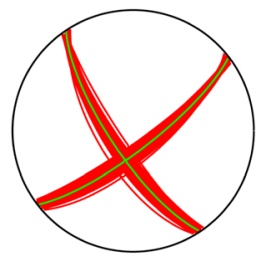

b

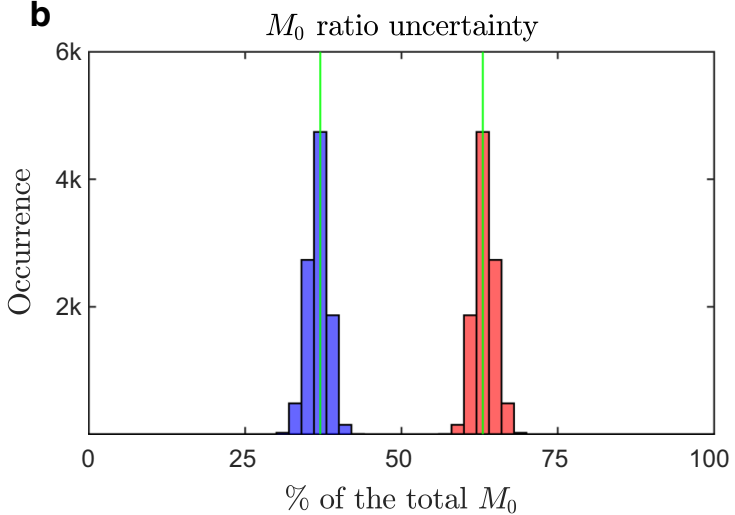

Minor DC uncert.

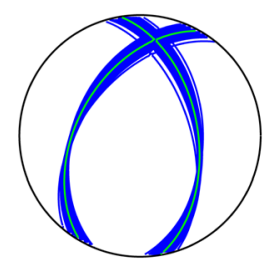

$\%$ of the total $M_{0}$
(
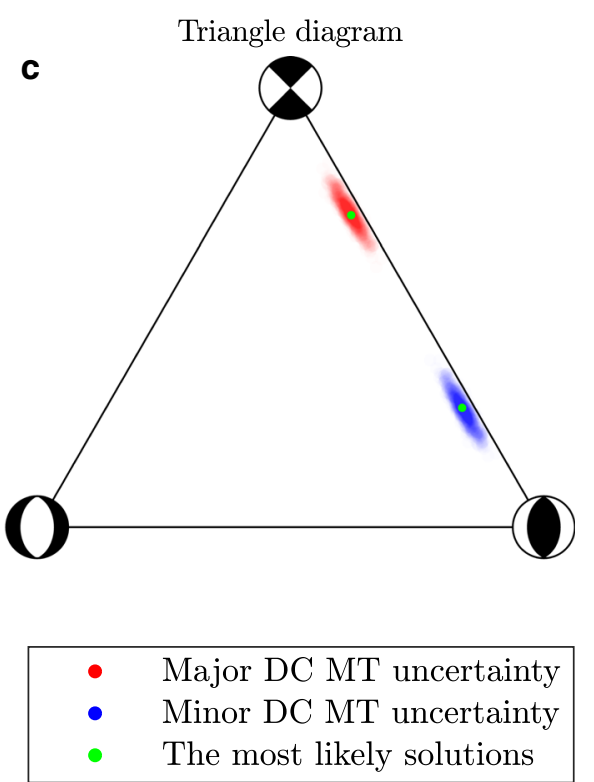

Fig. 5 Assessment of the uncertainty of the major and minor DC MTs decomposed from the whole posterior ensemble of 10,000 solutions (see text). a Perturbed nodal planes of the DC beach-ball in lower hemisphere projection. $\mathbf{b}$ Histogram of their mutual scalar seismic moment ratio. The triangle diagram (Frohlich 1992) with perturbed solutions in (c) indicates the uncertainty of the faulting type

in the layered velocity model from Table 2 (also used for the mainshock's CMT inference). Then, we determined the aftershocks' MTs from $P$-wave amplitudes and then inverted the local stress field.

\section{Data}

For the analysis of aftershocks, we used three-component waveforms recorded at 14 stations situated within $30 \mathrm{~km}$ from the mainshock epicenter. We used short-period stations (natural frequency $1 \mathrm{~Hz}$ ) from Hi-net network, broadband stations from F-net network (both operated by NIED, Okada et al. 2004, Obara et al. 2005), broadband stations operated by DPRI of Kyoto University and downhole short-period stations (natural frequency 1 or $2 \mathrm{~Hz}$ ) operated by Geological Survey of Japan, AIST (see Fig. 6). All of the waveform data are available through the NIED (Hi-net) data portal. Note that these stations were not used in the mainshock analysis as the records were saturated.

Special attention had to be paid to the processing of recordings from the downhole receivers GS.TKZ, GS.TNN, GS.ING. They were transformed to ENZ system from local XYZ systems of each of the stations assuming azimuth determined from a known position of 10 located $\mathrm{M}_{\mathrm{JMA}}>3.0$ events as follows. We presume that the $P$-wave arrival back-azimuth at a certain receiver is identical to the receiver-source azimuth. For the back-azimuth determination, the waveforms were bandpass filtered between $0.5 \mathrm{~Hz}$ and $15 \mathrm{~Hz}$. Resulting azimuthal rotations and standard deviations determined from the 10 events as listed in Table 5. As to the quality, the GS.TNN sensor exhibits much noisier data with unclear or inconsistent $P$-wave onsets and very long, disturbed wave trains when compared to those at GS.TKZ and GS.ING sensors. This is reflected also by the larger standard error of the GS.TNN azimuth (see Table 5).

All waveform data in digital format (bit counts) were converted to real units $(\mathrm{m} / \mathrm{s})$ using instrument constants, filtered by a bandpass filter and integrated into displacements. The used causal (one-way) bandpass filter between 2 and $15 \mathrm{~Hz}$ was determined empirically by manual inspection of waveforms and $P$-wave arrival shapes. The causality of the filter is advantageous for reconditioning of the direct wave arrivals (no signal prior the $P$-wave arrival). The filter corner frequencies were determined in order to include dominant frequency of direct $P$-wave arrivals while surpassing the background noise.

\section{Hypocenter determination}

We manually pick arrival times of direct $P$ - and $S$-waves on all stations (the earliest peak value). Then, hypocenters of analyzed events are located in 1D layered velocity model (Table 2) by our code utilizing probabilistic 


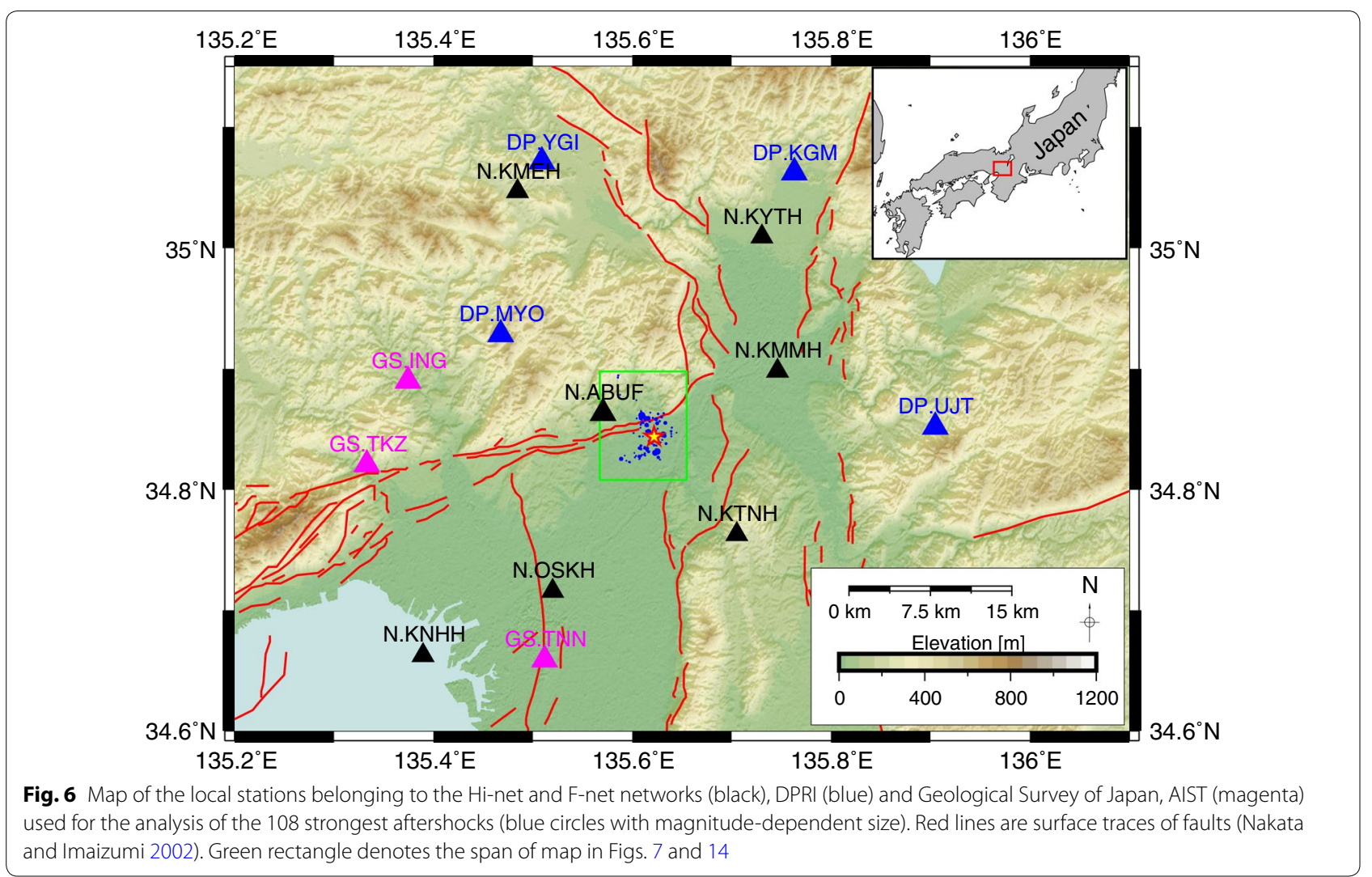

approach of Tarantola (2005, pp. 253-256). The uncertainties of arrival times are assumed to be Gaussian, originating from random perturbations of the velocity model with relative standard deviation of $10 \%$. A grid search over the area results in a 3D probability density function of the hypocenter location (see Additional file 1: Appendix III). The maximum likelihood model sample is used as the hypocenter location.

Locations of the 108 analyzed aftershocks are shown in Fig. 7 by colored circles. They are distributed in a cluster of irregular shape at a predominant depth of between 8 and $12 \mathrm{~km}$. Our hypocenter locations are very similar to those of the JMA unified hypocenter catalog.

Table 5 Rotations and standard deviations of downhole receivers

\begin{tabular}{lcc}
\hline Receiver & West-azimuth & STD error \\
\hline GS.TKZ & $23.6^{\circ}$ & $5.9^{\circ}$ \\
GS.TNN & $61.3^{\circ}$ & $10.5^{\circ}$ \\
GS.ING & $157.6^{\circ}$ & $5.1^{\circ}$
\end{tabular}

The list of the events used for the azimuth determination (MMDDHHMM): 06180842, 06181236, 06190031, 06190453, 06190650, 06190752, 06191415, $06200347,06232308,07011242$. These $M_{J A}>3.0$ events have clear $P$-wave arrival back-azimuths
Nevertheless, our locations have a minor relative systematical shift of 200-400 m toward east and approximately $2 \mathrm{~km}$ toward shallower depths. The uncertainties of hypocenter locations are estimated from the posterior PDFs as large as $500 \mathrm{~m}$ and $1.2 \mathrm{~km}(2 \sigma)$, in horizontal and vertical directions, respectively.

The cluster of hypocenters spreads mostly to the south from the ATTL which is steeply dipping northwards (HERP 2001). It spreads up to $3 \mathrm{~km}$ farther to the south from the surface traces of ATTL (see Fig. 7). Then, the irregular shape of the hypocenter cluster implies a complex geometry of the activated fault structure.

\section{Focal mechanisms}

In this study, we invert for deviatoric MTs of aftershocks using $P$-wave amplitudes. Synthetic $P$-wave amplitudes are evaluated using the layered velocity model (in Table 2) and our relocated hypocenters. The overdetermined inverse problem is then solved in Bayesian probabilistic framework assuming station-constant uncertainties of the $P$-wave amplitudes.

We first infer to deviatoric MTs of all the aftershocks without any station corrections. These preliminary solutions provide a reasonable fit of observations and synthetics, despite that the short-period signal is very sensitive 


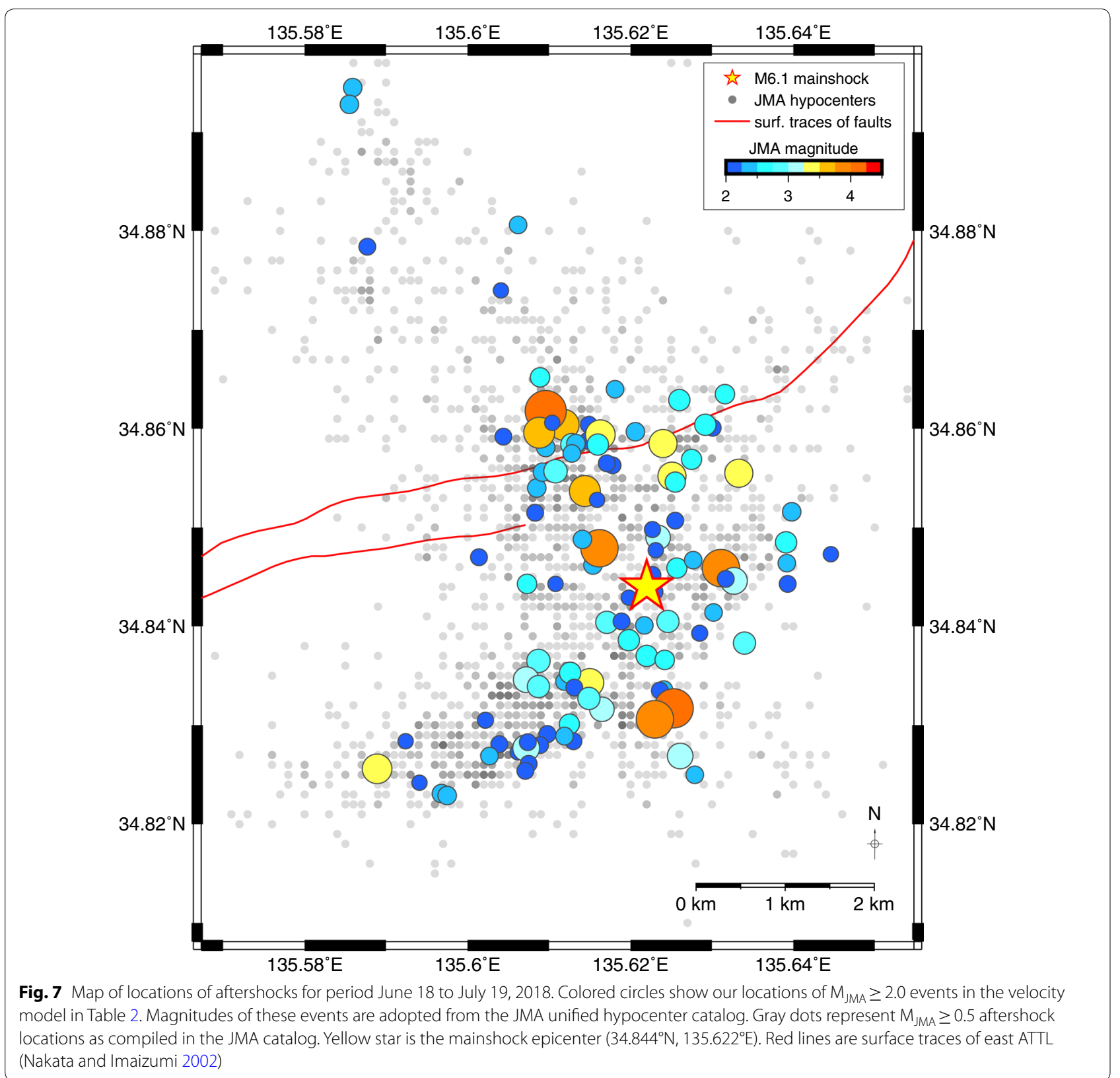

to the heterogeneous crustal structure. This inaccuracy is only partially compensated by the assumed uncertainties of $P$-wave amplitudes. Therefore, in the next step we take into account amplitude station corrections defined as the logarithmic average of the ratios between the theoretical and observed $P$-wave amplitudes at each station (Imanishi et al. 2011). We recalculate deviatoric MTs of all the aftershocks assuming the amplitude station corrections determined from the preliminary solutions.

As we use the Bayesian technique, solutions are supplemented by their uncertainties in the form of an ensemble of 10,000 random samples drawn from posterior PDF. The solution stability and data fit were manually checked on all events and stations. Figure 8 shows an example of inferred focal mechanism for $\mathrm{M}_{\mathrm{JMA}} 3.9$ aftershock that occurred on June 19, 2018. Despite the fact the nodal planes are reasonably well constrained (Fig. 8b), the DC component content is not, which is a general feature of the $P$-wave amplitude inversion method (see histogram in Fig. 8c). Hence, in the following, we interpret only the pure-shear components of the inverted aftershock MT solutions (DC to non-DC ratios are listed in Additional 
a
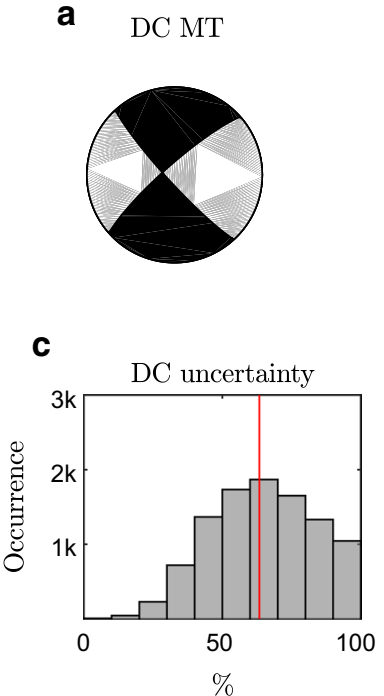

b

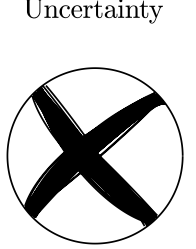

DOWN obs.

$\checkmark$ DOWN syn.

$\bigcirc$ UP obs.

$\checkmark$ UP syn.

Dobs. = syn.

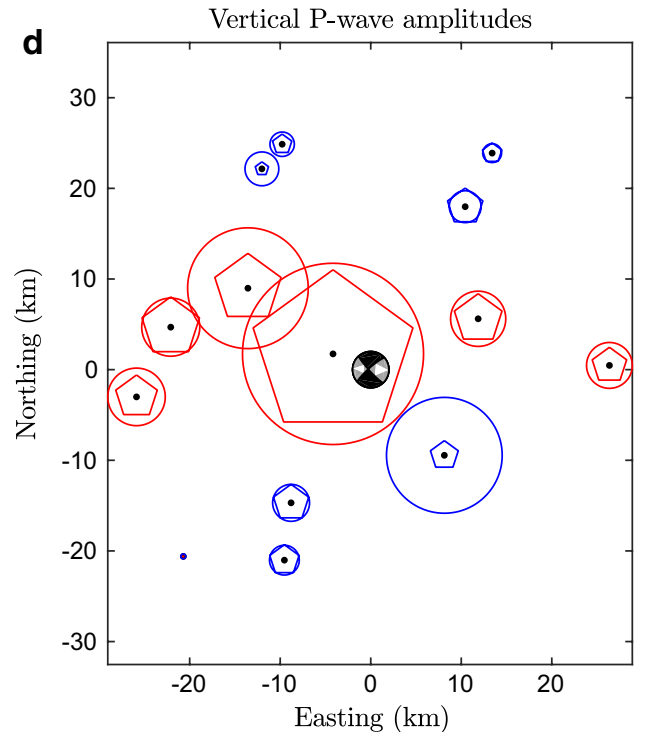

Fig. 8 Example of the focal mechanism solution for an aftershock ( $M_{\text {JMA }}$ 3.9) that occurred at 7:52 Japan Standard Time on June 19, 2018. a, b Inferred DC beach-ball and uncertainty of its nodal planes in lower hemisphere projection, respectively. c Shows histogram of the DC component content as captured by the ensemble of solutions. The map in (d) reveals fit of the observed (colored circles) and synthetic (colored pentagons) amplitudes on stations (black points) for the best source model (black beach-ball). The size of each colored symbol is proportional to the amplitude, while color has meaning of its sign (see legend)

file 1: Appendix IV). Finally, notice the good fit of the observed and synthetic amplitudes in Fig. 8d which has been improved by considering the amplitude station corrections.

We inspect and sort all aftershocks to three quality classes based on the MT solution stability, scatter of data misfit over stations (i.e., standard deviation of logarithms of ratios between the theoretical and observed amplitudes after applying the amplitude corrections) and DC component content of the maximum likelihood solution. The "A-class" aftershocks (31 in total) have stable MT solution with the most likely DC content larger than $70 \%$. These events have the least scatter of data misfits from all processed events. The "B-class" aftershocks (57 in total) have stable solution with the most likely DC content larger than 50\%. Finally, "C-class" events (20 in total) have the most likely DC content lower than 50\% and/or they have scatter of data misfit exceeding 90\% of all processed events. We consider "C-class" events to have poorly determined MTs; therefore, these events are excluded from the subsequent analysis.

Figure 9 shows maximum likelihood DC focal mechanisms of the A- and B-class aftershocks (88 in total). The solutions are color-coded according to their faulting type following the definition of Frohlich (1992) based on PNT-axes plunge angles (see legend in Fig. 9). The number of categorized strike-slip, reverse, normal and "odd" (i.e., other) events was $17,41,0$ and 30 , respectively.
There are no normal faulting events among the analyzed aftershocks. The strike-slip aftershocks (red beach-balls in Fig. 9) spread in a SW direction from the mainshock epicenter, while the reverse faulting events (blue beachballs in Fig. 9) are located mainly to the north and around the mainshock epicenter. Aftershocks of the "odd" faulting type (gray beach-balls in Fig. 9) are oblique faulting events combining strike-slip and reverse mechanism (see the triangle diagram in Fig. 9). The latter events are located mostly in the vicinity of strike-slip events. For better understanding of the spatial zonation of aftershocks' faulting type, see Fig. 10 with four vertical cross sections. Note especially cross sections AA' and DD' dominated by strike-slip (to oblique) and reverse faulting aftershocks, respectively. In summary, these results suggest that the source area is characterized by strike-slip to reverse faulting earthquakes (consistent with Matsushita and Imanishi 2015). The spatial zonation of aftershocks' faulting type may be related to a complex geometry of the activated structure located near ENE-WSW trending strike-slip and $\mathrm{N}-\mathrm{S}$ trending reverse faults.

In Fig. 11, we display the temporal evolution of the sequence. The figure shows the same set of the A- and B-class DC aftershock focal mechanisms as shown in Fig. 9 using different, time-dependent, color scale. The spatial-temporal distribution implies that almost the whole fault structure became active since the beginning of the sequence, and there is no significant migration 


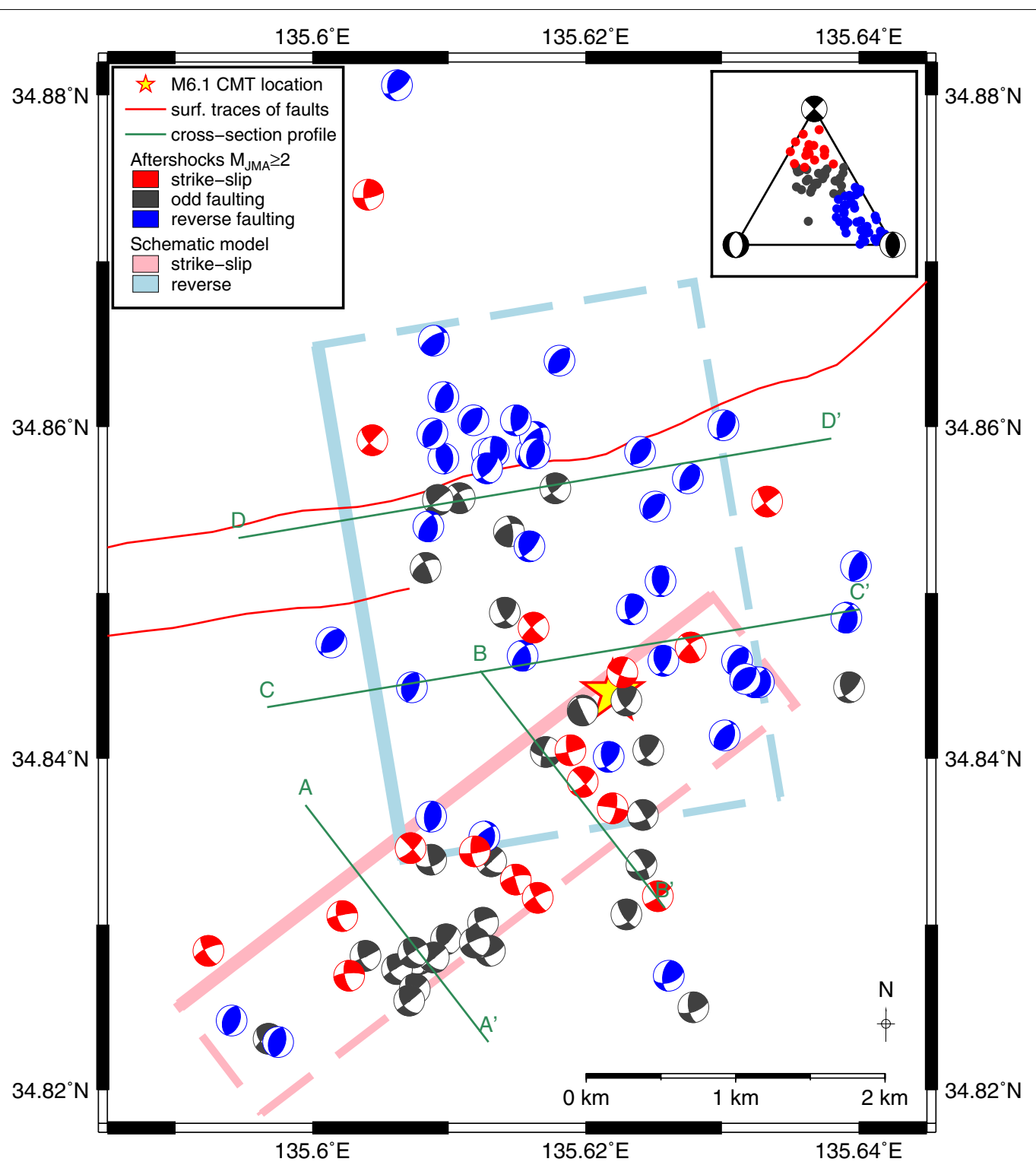

Fig. 9 Map of inverted pure-shear focal mechanisms (beach-balls in lower hemisphere projection) of the $M_{J M A} \geq 2.0$ aftershocks for period June 18 to July 19, 2018. The triangle diagram (upper right inset) by Frohlich (1992) is used for discrimination of the events' faulting type shown by color (see legend). Yellow star is the mainshock CMT location $\left(34.844^{\circ} \mathrm{N}, 135.622^{\circ} \mathrm{E}\right)$. Light-pink and light-blue lines represent the mainshock model coherent with its major and minor DC MT decomposition (see Fig. 14). Red lines are surface traces of east ATTL (Nakata and Imaizumi 2002)

of activity within the main focal zone (red and orange beach-balls in Fig. 11). The latest events located outside the main focal zone (green beach-balls in Fig. 11) may be regarded as spreading of the seismicity into surroundings of the primarily activated structure. Based on the aftershock locations, the primarily activated structure covers an area of approximately $5 \times 4 \mathrm{~km}$. Let us also point out that the triangle diagram in Fig. 11 implies that there was no significant temporal development of the faulting type during the 2018 northern Osaka sequence. This way, the strike-slip, reverse and oblique faulting type aftershocks occurred within the whole earthquake sequence.

The variation in strike, dip and rake angles for the investigated set of aftershocks is shown in Fig. 12. Nevertheless, the mechanisms of aftershocks depend on the present stress field after the mainshock occurrence and on the direction of pre-fractured faults; hence, these directions may vary. The strike-slips (right panels in Fig. 12) have the most frequent nodal plane azimuths at intervals $45-60^{\circ}$ and $135-150^{\circ}$. The 


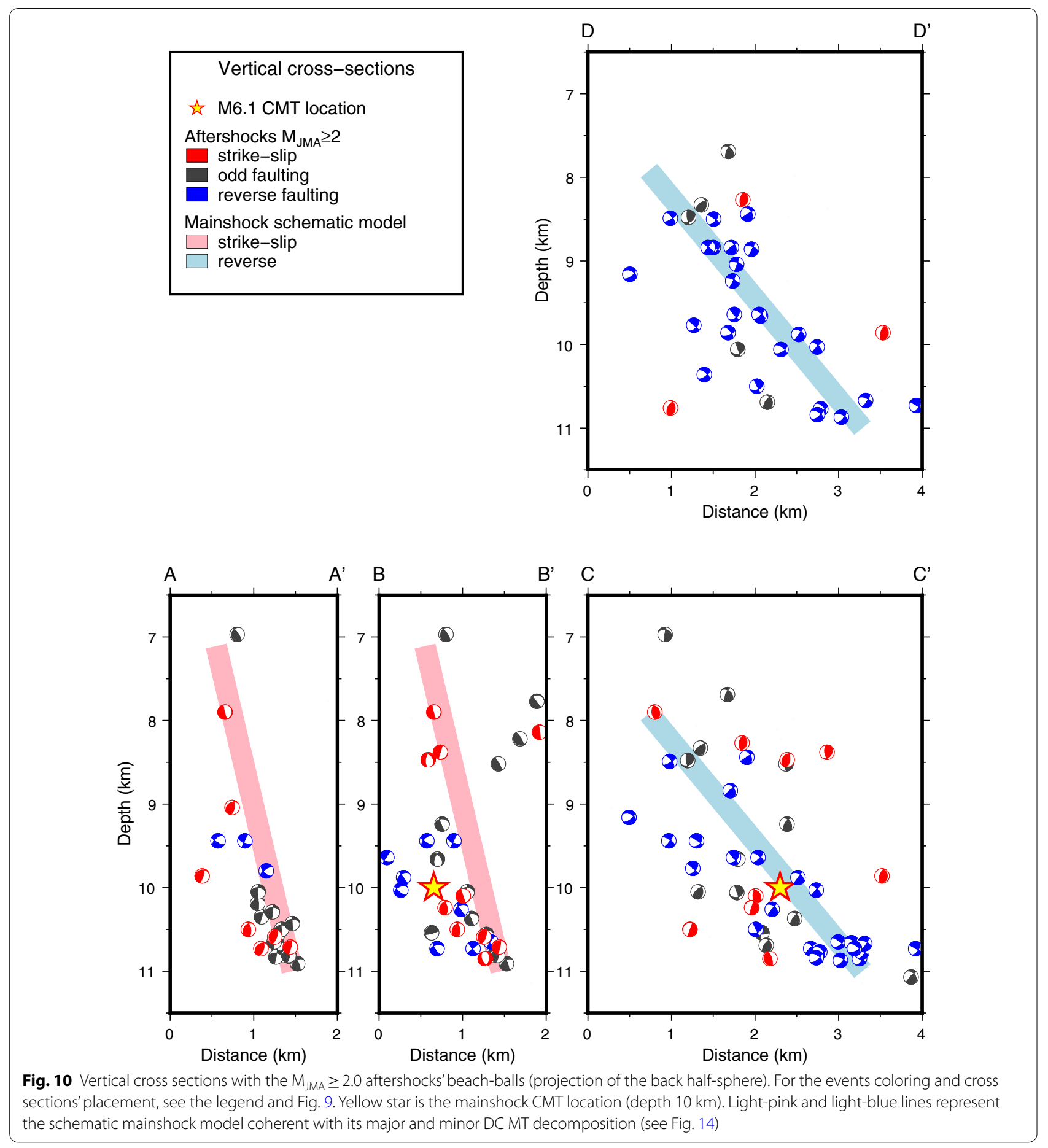

same values are represented by the steeply dipping odd events (mid panels in Fig. 12). The reverse faults in the left panels of Fig. 12 have dips of both nodal planes at intervals of $45-60^{\circ}$. Although the aftershocks' strike and dip angles vary, we may relate some directions with assumed mainshock's fault planes from the major and minor DC MT decomposition (green lines in Fig. 12). 


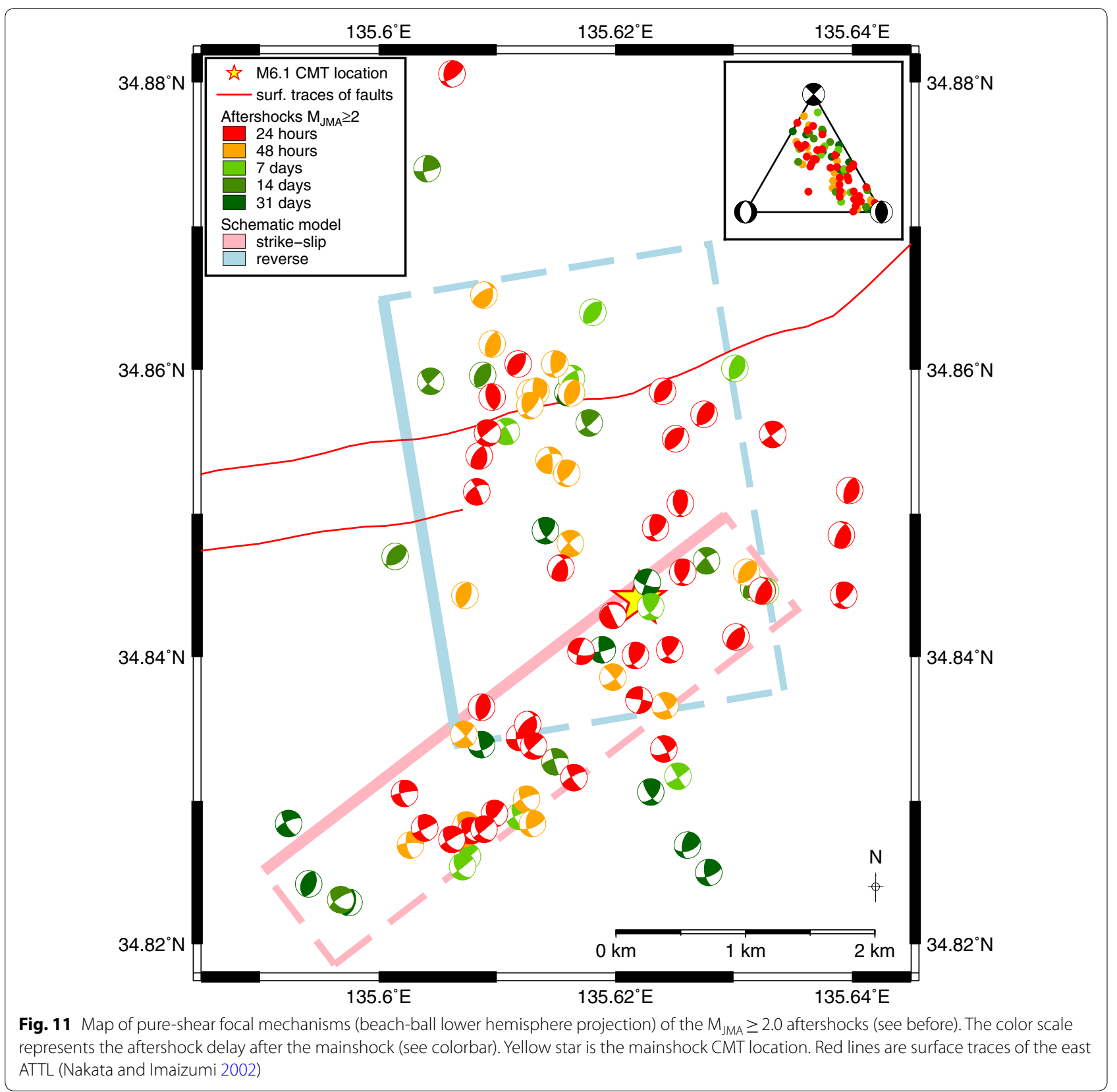

\section{Stress field in the northern Osaka}

The PT-axes of the determined DC focal mechanisms of A- and B-class aftershocks are shown in Fig. 13a-d by polar plots. The reverse faulting events have $P$-axis azimuths trending sub-horizontally from E-W to SE-NW (Fig. 13a), and their $T$-axes are sub-vertical. The strikeslip aftershocks have both $P$ - and $T$-axes, trending subhorizontally (Fig. 13c), where azimuths of $P$-axes are in the same range as for the reverse faulting events. The $P$-axes of the "odd" faulting events remain mainly subhorizontal having azimuths consistent with both the reverse and strike-slip events (see Fig. 13b). Finally, $P T$ axes of all the determined focal mechanisms are shown in Fig. 13d. The stability of the $P$-axes of all the aftershocks validates the plausibility of the non- $\mathrm{DC} \mathrm{M}_{\mathrm{w}} 5.6\left(\mathrm{M}_{\mathrm{JMA}} 6.1\right)$ mainshock decomposition into the major and minor DC MTs preserving the $P$-axis direction. The $P T$-axes of these two decomposed DC MTs are shown in Fig. 13a-d by green signs (see legend). These mainshocks' "major" and "minor" $P T$-axes are in accord with the aftershocks $\mathrm{PT}$-axes, and hence, there is no clear evidence of a change of the stress regime during this earthquake sequence. 


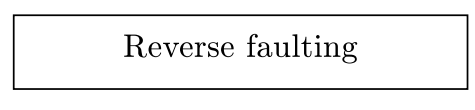

a Frequency of STRIKEs

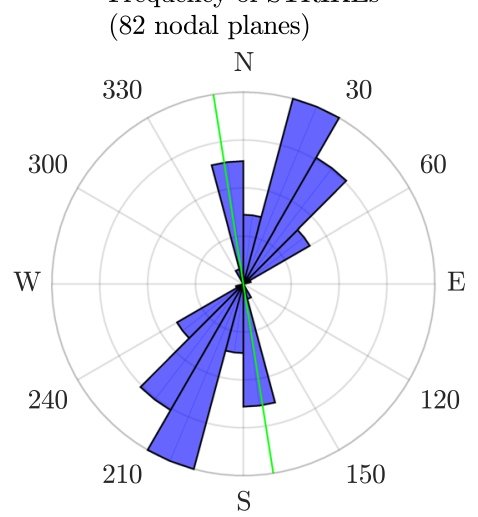

d

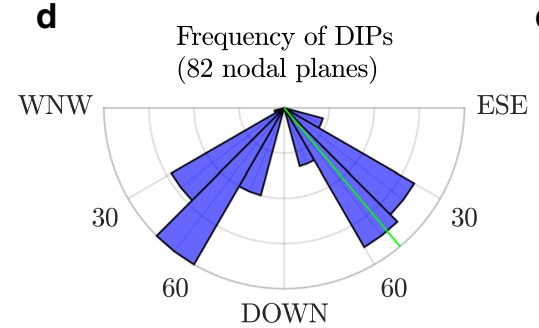

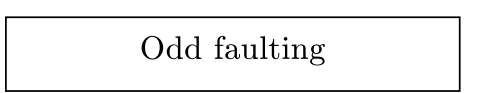

b

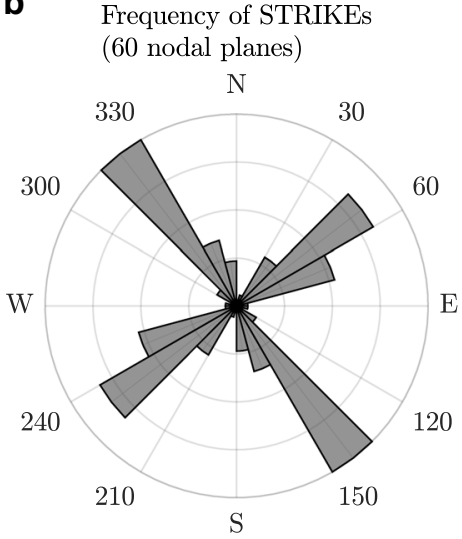

e

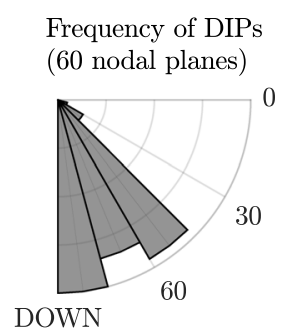

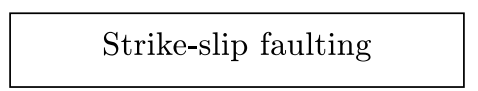

C
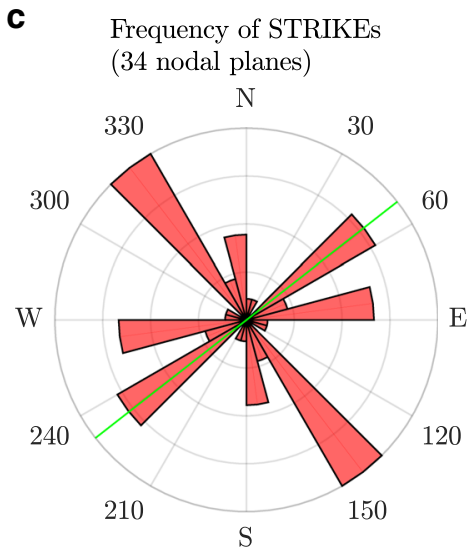

f

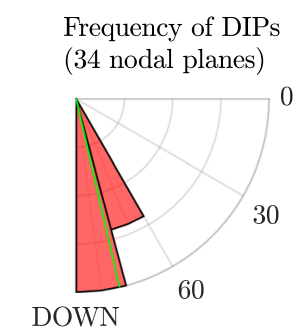

Frequency of DIPs (34 nodal planes)

Fig. 12 Occurrence frequencies of the azimuth (upper panels) and dip (bottom panels) angles of the aftershock focal mechanisms (for both nodal planes of each source) classified according to their faulting type (columns) following Frohlich (1992). Dips of the reverse faulting events (bottom left panel) are shown in projection to the vertical plane with azimuth WNW-ESE (N300 -N120 ). Green lines show angles of the assumed mainshock's fault planes from the major and minor DC MT decomposition (respective strike-slip or reverse fault planes)

The DC focal mechanisms of aftershocks (not the mainshock) are used to determine the local stress field by applying the inversion method by Michael (1984). It provides directions of maximum, intermediate and minimum principal stress axes $\left(\sigma_{1}, \sigma_{2}\right.$ and $\sigma_{3}$, respectively) and a shape ratio defined by Gephart and Forsyth (1984) as $R=\left(\sigma_{2}-\sigma_{1}\right) /\left(\sigma_{3}-\sigma_{1}\right)$. The method by Michael (1984) requires one to choose the actual fault plane from the two MT nodal planes; hence, we select the preferable nodal planes based on the local tectonic settings. Specifically, we select the east-dipping nodal planes of reverse mechanisms and the ENEWSW trending nodal planes of strike-slip and oblique mechanisms. The uncertainty of the stress field originating from uncertain focal mechanisms is illustrated by the Monte Carlo method, where the inversion is solved repeatedly over 10,000 realizations of random perturbations of strike and dip drawn from zero-mean Gaussian distribution with standard deviation of $20^{\circ}$ (Vavryčuk 2014).
The results of the stress field inversion for the northern Osaka area are shown in Fig. 13e (principal stress directions), Fig. 13f (the shape ratio) and Fig. 13g (the misfit angle). The inverted stress field parameters without any data perturbation (black-white markers in Fig. 13e) are described in Table 6. The maximum principal stress $\sigma_{1}$ is trending sub-horizontally in the ESE-WNW direction. The trend of $\sigma_{1}$ is stable, and it is clearly distinguished from the intermediate and the minimum principal stresses $\left(\sigma_{1} \gg \sigma_{2,3}\right)$. The shape ratio of 0.9 implies that the latter two principal stresses have almost the same size $\left(\sigma_{1} \gg \sigma_{2} \cong \sigma_{3}\right)$, which is also illustrated by the instability of $\sigma_{2,3}$ axes in the uncertainty analysis expressed by means of the random perturbations of the strike and dip angles. Our result is in accordance with that of Matsushita and Imanishi (2015) who conclude that the stable $\sigma_{1}$ axis is trending sub-horizontally and $\sigma_{2,3}$ axes vary spatially in the Kinki area. Nevertheless, we interpret the local instability of the $\sigma_{2,3}$ axes in the northern Osaka area by $\sigma_{2} \cong \sigma_{3}$. To 
a

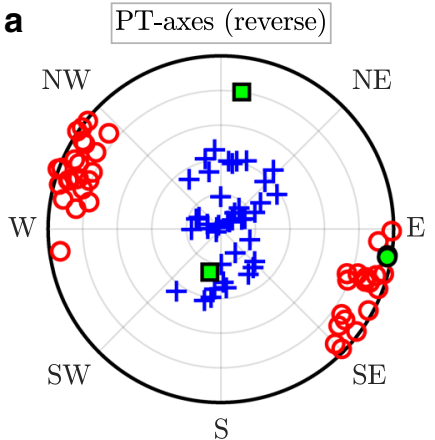

d

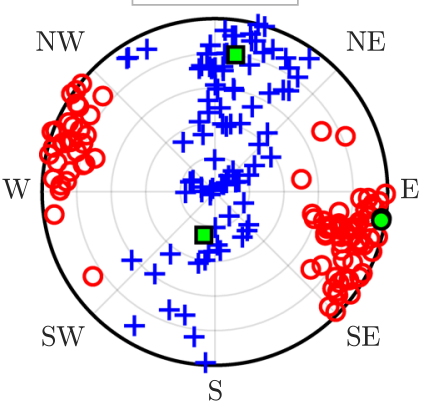

b

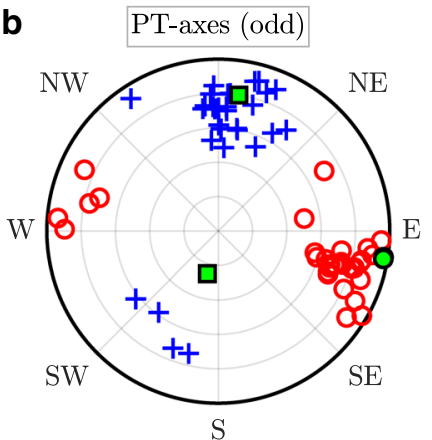

e Principal stress axes

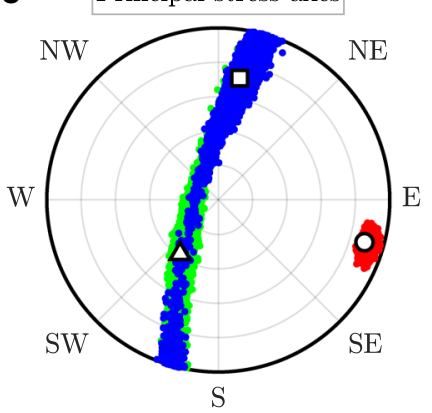

C PT-axes (strike-slip)

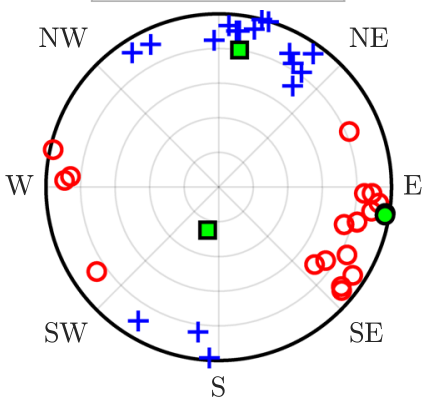

Shape ratio $R$

f

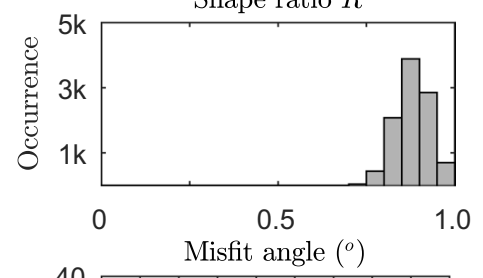

g

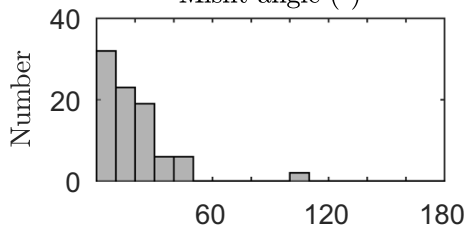

\begin{tabular}{ll}
\hline O & Aftershock P-axis \\
+ & Aftershock T-axis \\
O & Mainshock P-axis (major \& minor) \\
$\mathbf{\square}$ & Mainshock T-axis (major \& minor)
\end{tabular}

\begin{tabular}{|ll}
\hline $\mathbf{O}$ & $\sigma_{1}$ \\
$\boldsymbol{\Delta}$ & $\sigma_{2}$ \\
$\mathbf{\square}$ & $\sigma_{3}$ \\
\hline
\end{tabular}

Fig. 13 PT-axes of the aftershock focal mechanisms and the inverted stress field in the northern Osaka area. Polar plots in a-d show PT-axes of the aftershocks, and decomposed major and minor DC MTs of the mainshock (see bottom left legend and text). e Result of the local stress field inversion by Michael (1984)'s method with illustrated uncertainty (see bottom right legend and text). $\mathbf{f}$ Histogram of the shape ratio $R=\frac{\sigma_{2}-\sigma_{1}}{\sigma_{3}-\sigma_{1}} \cdot \mathbf{g}$ Histogram of misfit angles for the data with respect to the best stress field solution. The misfit angle is defined as an angle between the tangential traction predicted by the best stress field solution and the observed slip direction

Table 6 Inverted principal stress axis directions of the northern Osaka area from the aftershock mechanisms (method by Michael 1984)

\begin{tabular}{lrrr}
\hline $\boldsymbol{R}=\mathbf{0 . 9}$ & $\boldsymbol{\sigma}_{\mathbf{1}}$ & $\boldsymbol{\sigma}_{\mathbf{2}}$ & $\boldsymbol{\sigma}_{\mathbf{3}}$ \\
\hline Azimuth & $106^{\circ}$ & $215^{\circ}$ & $10^{\circ}$ \\
Plunge & $11^{\circ}$ & $59^{\circ}$ & $29^{\circ}$ \\
Error & $7^{\circ}$ & $66^{\circ}$ & $66^{\circ}$ \\
\hline
\end{tabular}

$R$ is the shape ratio of principal stress axes defined by Gephart and Forsyth (1984). As the error, we use $99 \%$ quantile of the angle between the inverted axis vector and all random realizations (inverse cosine of dot product)

conclude, the determined stress field for the northern Osaka area permits the simultaneous activation of both strike-slip and reverse faults.

\section{Discussion}

The adopted methods and source parameter uncertainties helped to distinguish which features of the inferred source parameters are reliable. For example, the presence of the strong CLVD component in the mainshock MT is statistically significant even considering imperfect knowledge of the Earth's crust. This allows us to use such detailed analysis as the major and minor DC MTs decomposition. On the other hand, the large uncertainty of the DC component content of the aftershocks prevents any physical interpretation. Finally, the uncertainty of the inverted stress field illustrates that the maximum principal stress $\sigma_{1}$ is stable in the area. 


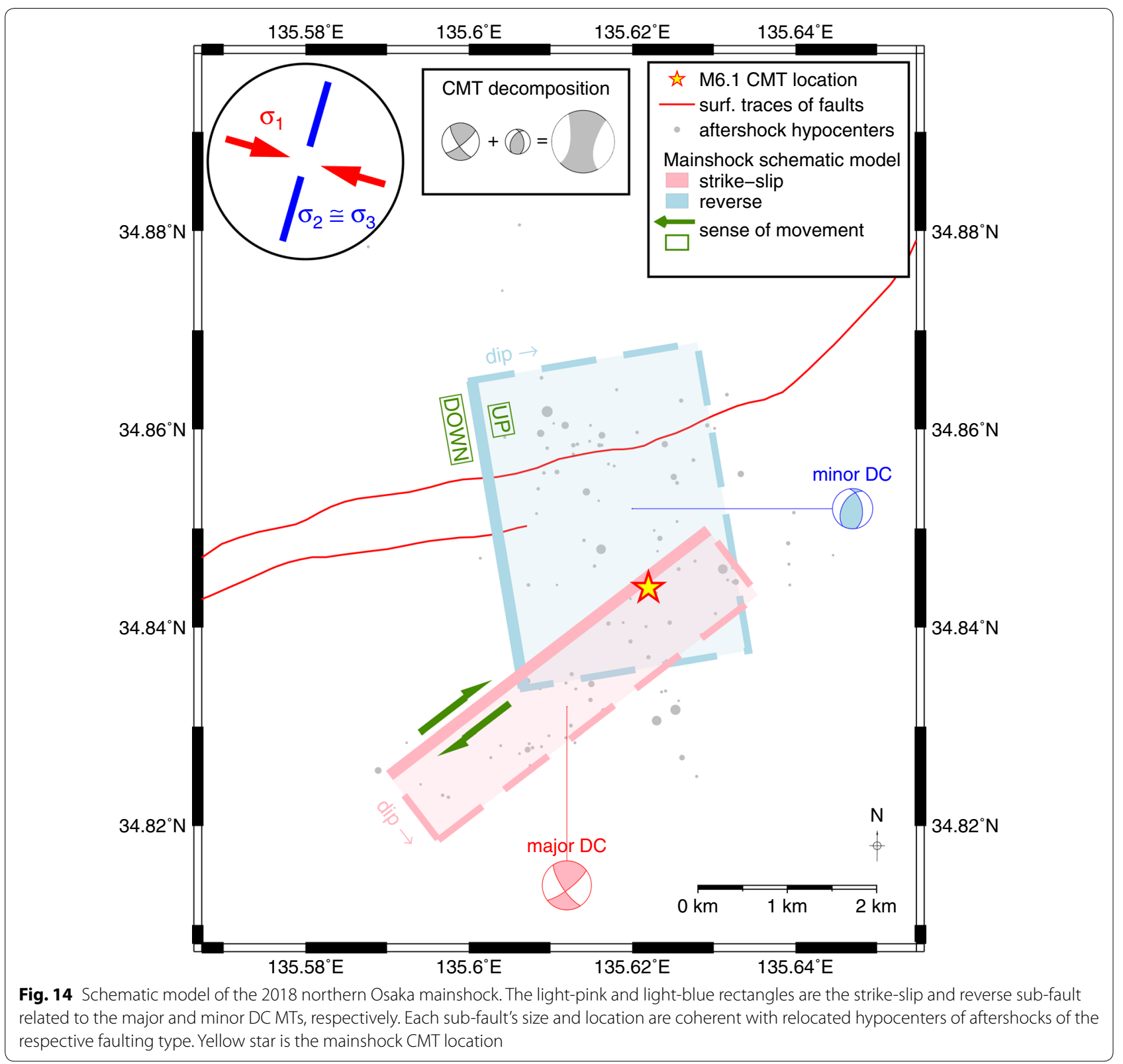

\section{Model of the mainshock rupture}

Here we propose a model of the mainshock rupture based on the decomposed major and minor DC mechanisms (Fig. 4 and Table 4) and the spatial distribution of aftershocks (Figs. 9, 10, 11). The schematic model of the mainshock is shown in Fig. 14. The assumed southeastdipping dextral strike-slip sub-fault (major DC MT) is situated at depths 7-11 km (see light-pink rectangle in Fig. 14). The sub-horizontal dextral movement on such a fault is then consistent with the dextral strike-slip movements on other nearby known faults. The east-dipping reverse sub-fault (minor DC MT) is situated at depths
8-11 km and partially overlaps with the strike-slip fault (see light-blue rectangle in Fig. 14).

The respective rupture areas of these assumed strikeslip and reverse sub-faults are proportional to the scalar seismic moments of the major and minor DC MTs (i.e., $63 \%$ and $37 \%$ ). The scalar seismic moment of the mainshock can be used for estimation of the total rupture area using an empirical scaling relationship. Here we adopt the empirical relationship from Somerville et al. (1999) that is based on the self-similar scaling of the large to midsize crustal earthquakes. The total rupture area of the mainshock is then estimated to be $44 \mathrm{~km}^{2}$ which is larger 
than the total area of our schematic model (i.e., $32 \mathrm{~km}^{2}$ ). However, we would like to emphasize that it is only an estimate, and the true rupture size may be influenced by joint activation of both of these nearby faults.

Our model of the mainshock is based on rather low frequencies (below $0.15 \mathrm{~Hz}$ ); hence, we cannot make conclusions about an exact timing of the two activated sub-faults which is below our resolution. Nevertheless, the focal mechanism of the mainshock as inverted from the $P$-waves first motion polarity by JMA (see Table 1 ) is a reverse faulting type similar to our minor DC MT (see Table 4). It suggests that the mainshock nucleated along the N-S trending reverse fault and then spread also along the dextral strike-slip fault. Our model of the mainshock is basically consistent with model by Kato and Ueda (2019) that was derived from spatiotemporal distribution of aftershocks relocated by double-difference method.

\section{Sesmotectonic interpretation}

Let us discuss relations of the activated faults in this sequence to the known local tectonic structures. The activated strike-slip fault has the strike angle trending similar to the eastern ATTL. However, the spatial distribution of the aftershocks implies that it is located a few $\mathrm{km}$ southwards from this distinctive tectonic line, which is steeply dipping northward (HERP 2001). Such a fault has not been known so far; nevertheless, parallel faulting is a common feature of this part of the Kinki triangle (e.g., Rokko faults). A known ENE-WSW trending strikeslip fault sub-parallel to the ATTL is the Itami fault, though it is traced more than $10 \mathrm{~km}$ to the west from the activated structure. Kawasaki et al. (1994) and Toda et al. (1995) found a graben structure on the southern side of ATTL based on a $P$-wave reflection profiling along Yodo River, east of the epicentral region. They interpreted the buried fault on the southern side of the graben structure as a normal fault. Katao (1996) reported a linear distribution of microearthquakes with strike-slip mechanism sub-parallel to ATTL, and this lineament includes the largest aftershock of the January 17, 1995, Kobe earthquake, occurring on the Itami fault. Thus, a sub-parallel buried fault might exist along the ATTL, and it is connected with the Itami fault. A part of the 2018 northern Osaka earthquake could be thought to have occurred on a part of this buried fault. Our results suggest that motion on this buried fault is dominated by strike-slip mechanism in the seismognenic depth. Regarding the activated reverse fault at the depth of $8-11 \mathrm{~km}$, its eastdipping nodal plane may suggest a relationship with the Uemachi fault zone having surface traces approximately $12 \mathrm{~km}$ to the west. The deeper segments of the Uemachi fault are expected to have a smaller (thrust-like) dip angle (e.g., Sato et al. 2009), but the activated structure has a dip angle of $50^{\circ}$. Moreover, there is no evidence of an extensive seismic activity migration to the south along the Uemachi fault. So, the tectonic relationship between them remains unclear.

Let us discuss a possible relation of the 2018 northern Osaka $\mathrm{M}_{\mathrm{w}} 5.6\left(\mathrm{M}_{\mathrm{JMA}}\right.$ 6.1) earthquake with the 1995 Hyogoken-Nanbu (Kobe) $\mathrm{M}_{\mathrm{w}} 6.9\left(\mathrm{M}_{\mathrm{JMA}} 7.2\right)$ earthquake. Following Toda et al. (1998), the Kobe earthquake influenced significantly the stress of nearby faults. Particularly for the northern Osaka area, the Coulomb failure stress on optimally oriented strike-slip faults increased by up to 3 bars (alike eastern ATTL). This means that the preexisting strike-slip faults might have been brought closer to failure by the Kobe earthquake. Contrarily, the Coulomb failure stress change from the Kobe earthquake on optimally oriented thrust faults is almost zero in northern Osaka. The change is negative to the south and positive to the north from the 2018 earthquake epicenter. Regarding the seismicity, the largest $\mathrm{M}_{\mathrm{JMA}} 5.4$ aftershock of the Kobe earthquake occurred east from the Rokko faults on the Itami fault (e.g., Katao et al. 1997). Hence, there was also evidence of an activity on a strike-slip fault sub-parallel to the ATTL.

\section{Conclusion}

In this study, we performed detailed analysis of the mainshock-aftershocks 2018 northern Osaka earthquake sequence from seismological point of view. We use methods and approaches which take into account uncertainties of measured data and/or imperfect knowledge of the Earth's crust. The solutions are thus complemented by an estimate of uncertainties, which helps in interpretations by pointing out robust features of inverted source parameters. Although this work is mostly a case study, some of the methods are enhanced or tailor-made for the local settings (e.g., major and minor DC MT decomposition). The source codes for some of the used methods are available on the author's website (http://geo.mff.cuni. $\mathrm{cz} / \sim$ hallo/).

Results from the 2018 northern Osaka sequence analysis imply that the $\mathrm{M}_{\mathrm{w}} 5.6\left(\mathrm{M}_{\mathrm{JMA}} 6.1\right)$ mainshock is characterized by a geometrically complex rupture process. The activated fault structure consists of at least two (major and minor) segments with diverse geometries and slip directions intersecting under Takatsuki city. The activated ENE-WSW trending strike-slip fault is parallel to the ATTL, while the N-S trending reverse fault has a dip of $50^{\circ}$ to the east. Shear movements on both of these faults contribute significantly to the total seismic moment of the mainshock. Therefore, the mainshock rupture process is the case of joint movements on the strike-slip and reverse faults. 
The series of weaker aftershocks occurred mainly within the primarily activated fault structure during the mainshock. The hypocenter cluster of aftershocks has an irregular shape, spreading mainly south from the ATTL. These aftershocks exhibit strike-slip to reverse faulting type consistently with the major and minor sub-sources decomposed from the mainshock. There is no significant temporal evolution of the faulting type during the aftershocks' sequence, which suggests that both faults were activated during the mainshock. These conclusions are supported by the inverted local stress field from the aftershock mechanisms, showing that the maximum principal stress is trending sub-horizontally in the ESEWNW direction. It is clearly distinct from the intermediate and minimum stresses, which have almost the same size. Such stress field allows for simultaneous activation of both strike-slip and reverse faults.

The lesson learned from the complex rupture process of the 2018 northern Osaka mainshock is that seismic hazard assessment and future urban planning should take into account such cases of complex faulting. Specifically, the seismic hazard in areas with one dominant stress axis (like $\sigma_{1} \gg \sigma_{2} \cong \sigma_{3}$ ) should take into account possible joint movements on preexisting faults of diverse geometries (joint movements on strike-slip and reverse faults). Nevertheless, we acknowledge that this task is challenging for buried or even unknown faults as in the present case.

\section{Additional file}

Additional file 1. Supplementary file containing appendices I-IV with additional figures, tables and methods.

\section{Author details}

${ }^{1}$ Faculty of Mathematics and Physics, Charles University, Prague, Czech Republic. ${ }^{2}$ The Institute of Technology and Business in České Budějovice, České Budějovice, Czech Republic. ${ }^{3}$ Disaster Prevention Research Institute, Kyoto University, Gokasho, Uji, Kyoto, Japan.

\section{Acknowledgements}

Authors thank all operators involved in station maintenance of K-NET, KiK-net, Hi-net and F-net networks (NIED). We also acknowledge all operators involved in maintenance of stations operated by DPRI of Kyoto University, JMA Earthquake and Tsunami Observation Network and Geological Survey of Japan, AIST. The JMA unified earthquake catalog is produced by JMA in cooperation with the Ministry of Education, Culture, Sports, Science and Technology (MEXT). Generic Mapping Tools (Wessel and Smith 1998) was used to draw the figures. The topography in maps originates from the SRTM-90 m digital elevation data produced originally by NASA. We are grateful to two anonymous reviewers for their comments that improved the original manuscript.

\section{Competing interests}

The author declares that they have no competing interests.

\section{Availability of data and materials}

The data that support the findings of this study are available at the NIED Data Management Center, [https://hinetwww1 1.bosai.go.jp/auth/?LANG=en] and NIED Strong-motion Data Center [http://www.kyoshin.bosai.go.jp/kyoshin/ search/index_en.html].

\section{Consent for publication}

Not applicable.

\section{Ethics approvals and consent to participate}

Not applicable.

\section{Funding}

We acknowledge financial support by the Grant Agency of the Charles University project GAUK-728916, Charles University grant SVV-260447 and the Czech Science Foundation project 18-06716J. The paper was supported by RUMOBIL CENTRAL EUROPE 55.

\section{Publisher's Note}

Springer Nature remains neutral with regard to jurisdictional claims in published maps and institutional affiliations.

Received: 30 November 2018 Accepted: 18 March 2019

Published online: 27 March 2019

\section{References}

AIST: National Institute of Advanced Industrial Science and Technology; ATTL: Arima-Takatsuki Tectonic Line; BP: Before present; CLVD: Compensated linear vector dipole; CMT: Centroid moment tensor; DC: Double couple; DPRI: Disaster Prevention Research Institute; GF: Greens'function; HERP: Headquarters for Earthquake Research Promotion; InSAR: Interferometric synthetic aperture radar; ISO: Isotropic; JMA: Japan Meteorological Agency; MEXT: Ministry of Education, Culture, Sports, Science and Technology; MT: Moment tensor; NASA: National Aeronautics and Space Administration; NIED: National Research Institute for Earth Science and Disaster Resilience; PDF: Probability density function; PGA: Peak ground acceleration; SRTM: Shuttle Radar Topography Mission; USGS: United States Geological Survey.

\section{Authors' contributions}

$\mathrm{MH}$ analyzed the mainshock and aftershocks data, coded the processing software and drafted the manuscript including figures. IO analyzed the aftershocks data and contributed with processing of downhole receivers. KA supported the research by knowledge of the local seismotectonic conditions and enhanced paper by the interpretation of results. FG contributed mainly in methodology and with primary draft corrections. All authors read and approved the final manuscript.
Aki K, Richards P (2002) Quantitative seismology, 2nd edn. University Science Books, Sausalito. ISBN 0-935702-96-2

Bouchon M (1981) A simple method to calculate Green's functions for elastic layered media. Bull Seismol Soc Am 71:959-971

Duputel Z, Rivera L, Fukahata Y, Kanamori H (2012) Uncertainty estimations for seismic source inversions. Geophys J Int 190(2):1243-1256. https://doi. org/10.1111/j.1365-246X.2012.05554.x

Frohlich C (1992) Triangle diagrams: ternary graphs to display similarity and diversity of earthquake focal mechanisms. Phys Earth Planet Inter 75:193-198

Frohlich C (1994) Earthquakes with non-double-couple mechanisms. Science 264:804-809

Gephart JW, Forsyth DW (1984) An improved method for determining the regional stress tensor using earthquake focal mechanism data: application to the San Fernando earthquake sequence. J Geophys Res 89:9305-9320

Hallo M, Gallovič F (2016) Fast and cheap approximation of Green functions uncertainty for waveform-based earthquake source inversions. Geophys J Int 207:1012-1029. https://doi.org/10.1093/gji/ggw320

Hallo M, Asano K, Gallovič F (2017) Bayesian inference and interpretation of centroid moment tensors of the 2016 Kumamoto earthquake sequence, 
Kyushu, Japan. Earth Planets Space 69:134. https://doi.org/10.1186/s4062 3-017-0721-4

Headquarters for Earthquake Research Promotion (2001) Long-term evaluation of the Arima-Takatsuki fault zone, http://www.jishin.go.jp/main/ chousa/01jun_arima/index.htm. Accessed 15 Nov 2018 (in Japanese)

Headquarters for Earthquake Research Promotion (2004) Long-term evaluation of the Uemachi fault zone, http://www.jishin.go.jp/main/chous a/04mar_uemachi/index.htm. Accessed 22 Oct 2018 (in Japanese)

Hirata N, Kimura R (2018) The Earthquake in Ōsaka-Fu Hokubu on 18 June 2018 and its Ensuing Disaster. J Disaster Research 13(4):813-816

Huzita K (1962) Tectonic development of the median zone (Setouti) of Southwest Japan, since the Miocene. J Geosci Osaka City Univ 6(4):103-143

Huzita K (1969) Tectonic development of Southwest Japan in the quaternary period. J Geosci Osaka City Univ 12(5):53-70

Imanishi K, Kuwahara Y, Takeda T, Mizuno T, Ito H, Ito K, Wada H, Haryu Y (2011) Depth-dependent stress field in and around the Atotsugawa fault, central Japan, deduced from microearthquake focal mechanisms: evidence for localized aseismic deformation in the downward extension of the fault. J Geophys Res 116:B01305

Ishibashi I (2004) Status of historical seismology in Japan. Ann Geophys 47:339-368

Jost ML, Herrmann RB (1989) A student's guide to and review of moment tensors. Seismol Res Lett 60:37-57

Kamai T, Sangawa A (2011) Landslides on ancient embankments in the Kinki district (Japan): strong motion seismoscope of the 1596 Keichou-Fushimi earthquake. Quat Int 242:90-105

Kanamori H (1995) The Kobe (Hyogo-ken Nanbu), Japan, earthquake of January 16, 1995. Seismol Res Lett 66(3):6-10

Kanamori H, Given JW (1981) Use of long-period surface waves for rapid determination of earthquake-source parameters. Phys Earth Planet Inter 27(1):8-31

Katao H (1996) Seismicity around the rupture zone of the Hyogoken-Nanbu earthquake. Report Coord Comm Earthq Predict Jpn 55:508-515 (in Japanese)

Katao H, Maesa N, Hiramatsu Y, lio Y, Nakao S (1997) Detailed Mapping of Focal Mechanisms in/around the 1995 Hyogo-ken Nanbu Earthquake Rupture Zone. J Phys Earth 45:105-119

Kato A, Ueda T (2019) Source fault model of the 2018 M 5.6 northern Osaka earthquake, Japan, inferred from the aftershock sequence. Earth Planets Space 77:11. https://doi.org/10.1186/s40623-019-0995-9

Kawasaki S, Toda S, Nakagawa K, Kobayashi Y (1994) Seismic reflection exploration in the eastern part of the Arima-Takatsuki tectonic line, Kinki District, Central Japan. J Seismol Soc Jpn 2nd Ser 47(2):173-182 (in Japanese)

Kikuchi M, Kanamori H (1991) Inversion of complex body waves - III. Bull Seismol Soc Am 81(6):2335-2350

Koketsu K, Miyake H, Suzuki H (2012) Japan integrated velocity structure model version 1. In: Proceedings of the 15th world conference on earthquake engineering, Lisbon, 24-28 September 2012

Liu J, Li L, Zahradník J, Sokos E, Liu C, Tian X (2018) North Korea's 2017 test and its nontectonic aftershock. Geophys Res Lett 45:2018GL077095

Ma J, Dineva S, Cesca S, Heimann S (2018) Moment tensor inversion with three-dimensional sensor configuration of mining induced seismicity (Kiruna mine, Sweden). Geophys J Int 213(3):2147-2160

Maruyama T, Lin A (2000) Tectonic history of the Rokko active fault zone (southwest Japan) as inferred from cumulative offsets of stream channels and basement rocks. Tectonophysics 323:197-216

Maruyama T, Lin A (2002) Active strike-slip faulting history inferred from offsets of topographic features and basement rocks: a case study of the ArimaTakatsuki Tectonic Line, southwest Japan. Tectonophysics 344:81-101

Matsushita R, Imanishi K (2015) Stress fields in and around metropolitan Osaka, Japan, deduced from microearthquake focal mechanisms. Tectonophysics 642:46-57

Michael AJ (1984) Determination of stress from slip data: faults and folds. J Geophys Res 89(B13):11517-11526

Mustać M, Tkalčić H, Burky A (2018) The variability and interpretation of earthquake source mechanisms in the Geysers geothermal field from a
Bayesian standpoint based on the choice of a noise model. J Geophys Res Solid Earth 123(1):513-532

Nakata T, Imaizumi T (2002) Digital active fault map of Japan. University of Tokyo Press, Tokyo (in Japanese)

Obara K, Kasahara K, Hori S, Okada Y (2005) A densely distributed high-sensitivity seismograph network in Japan: Hi-net by National Research Institute for Earth Science and Disaster Prevention. Rev Sci Instrum 76:021301

Okada A (1980) Quaternary faulting along the Median Tectonic Line of southwest Japan. Mem Geol Soc Jpn 18:79-108

Okada Y, Kasahara K, Hori S, Obara K, Sekiguchi S, Fujiwara H, Yamamoto A (2004) Recent progress of seismic observation networks in Japan: Hi-net, F-net, K-NET and KiK-net. Earth Planets Space 56:15-28. https://doi. org/10.1186/BF03353076

Research Group for Active Faults of Japan (1991) Active Faults in Japan, Revised edn. University of Tokyo Press, Tokyo (in Japanese)

Sato H, Ito K, Abe S, Kato N, Iwasaki T, Hirata N, Ikawa T, Kawanaka T (2009) Deep seismic reflection profiling across active reverse faults in the Kinki Triangle, central Japan. Tectonophysics 472:86-94

Somerville P, Irikura K, Graves R, Sawada S, Wald D, Abrahamson N, Iwasaki Y, Kagawa T, Smith N, Kowada A (1999) Characterizing crustal earthquake slip models for the prediction of strong ground motion. Seismol Res Lett 70(1):59-80

Sugito N, Kondo H (2015) Most recent faulting event in the Uemachi fault zone and related changes in the geomorphic environment of the Kawachi plain, southwest Japan. J Geogr (Chigaku Zasshi) 124(4):607-631 (in Japanese with English abstract)

Sugiyama Y, Mizuno K, Nanayama F, Sugai T, Yokota H, Hosoya T, Miura K, Takemura K, Kitada N (2003) Study of blind thrust faults underlying Tokyo and Osaka urban areas using a combination of high-resolution seismic reflection profiling and continuous coring. Ann Geophys 46(5):1071-1085

Tanaka Y (1985) Crustal stress measurement and earthquake prediction. J Geod Soc Jpn 31(1):73-85

Tarantola A (2005) Inverse problem theory and methods for model parameter estimation. Society for Industrial and Applied Mathematics, Philadelphia. ISBN 0-89871-572-5

Terakawa T, Matsuura M (2010) The 3-D tectonic stress fields in and around Japan inverted from centroid moment tensor data of seismic events. Tectonics 29:TC6008

Toda S, Kawasaki S, Takemura K, Okada A (1995) Graben structures along the Arima-Takatsuki Tectonic Line inferred from seismic reflection sections. $J$ Seismol Soc Jpn 2nd Ser 48(4):511-520 (in Japanese)

Toda S, Stein RS, Reasenberg PA, Dieterich JH, Yoshida A (1998) Stress transferred by the $1995 \mathrm{Mw}=6.9$ Kobe, Japan, shock: effect on aftershocks and future earthquake probabilities. J Geophys Res 103:24543-24565

Ulrich T, Gabriel A-A, Ampuero J-P, Xu W (2019) Dynamic viability of the 2016 Mw 7.8 Kaikoura earthquake cascade on weak crustal faults. Nat Commun 10:1213

Vackáŕ J, Gallovič F, Burjánek J, Zahradník J, Clinton J (2017) Bayesian ISOLA: new tool for automated centroid moment tensor inversion. Geophys J Int 210(2):693-705

Vavryčuk V (2014) Iterative joint inversion for stress and fault orientations from focal mechanisms. Geophys J Int 199(1):69-77

Wakita K (2013) Geology and tectonics of Japanese islands: a review-the key to understanding the geology of Asia. J Asian Earth Sci 72:75-87

Wallace TC (1985) A Reexamination of the moment tensor solutions of the 1980 Mammoth lakes earthquakes. J Geophys Res 90:11171-11176

Wessel P, Smith WHF (1998) New, improved version of generic mapping tools released. EOS Trans Am Geophys Union 79:579

Yagi Y, Fukahata Y (2011) Introduction of uncertainty of Green's function into waveform inversion for seismic source processes. Geophys J Int 186(2):711-720

Zahradník J, Custódio S (2012) Moment tensor resolvability: application to Southwest Iberia. Bull Seismol Soc Am 102(3):1235-1254

Zahradník J, Sokos E (2018) ISOLA code for multiple-point source modeling: review. In: D'Amico S (ed) Moment tensor solutions: a useful tool for seismotectonics. Springer, Berlin 